NBER WORKING PAPER SERIES

\author{
FEES AND SURCHARGING IN \\ AUTOMATIC TELLER MACHINE NETWORKS: \\ NON-BANK ATM PROVIDERS VERSUS LARGE BANKS \\ Elizabeth W. Croft \\ Barbara J. Spencer \\ Working Paper 9883 \\ http://www.nber.org/papers/w9883
}
NATIONAL BUREAU OF ECONOMIC RESEARCH
1050 Massachusetts Avenue
Cambridge, MA 02138
July 2003

The views expressed herein are those of the authors and not necessarily those of the National Bureau of Economic Research.

(C)2003 by Elizabeth W. Croft and Barbara J. Spencer. All rights reserved. Short sections of text, not to exceed two paragraphs, may be quoted without explicit permission provided that full credit, including (C) notice, is given to the source. 
Fees and Surcharging in automatic teller machine networks:

Non-bank ATM providers versus large banks

Elizabeth W. Croft and Barbara J. Spencer

NBER Working Paper No. 9883

July 2003

JEL No. L1, G2

\begin{abstract}
This paper develops a spacial model of ATM networks to explore the implications for banks and non-banks of interchange fees, foreign fees and surcharges applied to transactions by customers at other than an own-bank ATM. Surcharging raises the price (foreign fee plus surcharge) paid by customers above the joint profit-maximizing level achieved by setting the interchange fee at marginal cost and not surcharging. Similar size banks would agree not to surcharge, but such an agreement is typically not possible between a bank and a non-bank. A high cost of teller transactions modifies the tendency towards high ATM fees.
\end{abstract}

Elizabeth W. Croft

Business Program

University of Northern BC.

3333 University Way, Prince George

B.C. V2N 4Z9, Canada

crofte@unbc.ca
Barbara J. Spencer

Sauder School of Business

University of British Columbia

2053 Main Mall, Vancouver

B.C. V6T1Z2, Canada

and NBER

barbara.spencer@sauder.ubc.ca 


\section{Fees and surcharging in automatic teller machine networks: Non-bank ATM providers versus large banks}

\section{Introduction}

The wide-spread introduction of surcharges on ATM (Automatic Teller Machine) transactions in North America has become a high profile issue, creating concern among consumer advocates and public policy makers about disclosure and fairness in ATM fees. Surcharges proliferated after April 1996 when, in response to pressure from State governments and the courts, both of the U.S. national ATM networks, Cirrus and Plus, lifted the prohibition they had maintained on surcharging up to that point. ${ }^{1}$ At the same time the networks agreed to allow the entry of nonbanks. Non-banks provide only ATM services, whereas banks typically both own ATMs and issue cards so that customers can access ATMs. As we will show, network membership by non-banks has significant implications in raising the fees that customers have to pay for ATM transactions.

ATM networks were initially developed as a means by which banks could save costs by shifting customers from costly "teller" transactions using personnel at a branch to the use of machines. In the early 1980s in North America, these initially proprietary systems evolved into shared networks, which enhanced consumer convenience in accessing their account, without having to go to their branch. A main fee set by the (shared) network is an "interchange fee" that banks must pay to other member firms for each transaction made by one of their customers at another member's

\footnotetext{
${ }^{1}$ Surcharging was first allowed in 1989 by Pulse Electronic Funds Transfer Association as a result of a binding arbitration ruling. Plus and Cirrus subsequently faced the threat of a legal challenge to their surcharging ban by ATM owners on anti-trust grounds. The networks were also under pressure from new laws and regulations in 15 states that permitted surcharging. See Ruud and Webre (1998).
} 
$\mathrm{ATM}^{2}$ In order to recover at least part of the cost, banks typically charge their own customers a "foreign fee" for these transactions. In addition to the foreign fee, customers making ATM transactions at other than their own bank may pay a "surcharge" directly to the owner of the ATM. This fee structure has the interesting and unusual feature that all three fees apply to the same transaction. Even apart from effects on consumer welfare, this raises the question as to the differing incentives of network members that drive these three fees.

This paper considers the profit implications of all three fees (interchange fees, foreign fees and surcharges) in the context of a spatial model of ATM networks in which consumers move around the "city" as represented by a circular network of ATMs. Consumers face a tradeoff between the inconvenience of travelling to the closest ATM of their own bank and the total price, the sum of the foreign fee and surcharge, that they must pay for a transaction at other ATMs. Consumers may also choose to travel to the branch of their bank so as to use a teller. Banks charge an up-front fee for a banking package that allows customers to make transactions at an own-bank ATM or an inbranch teller at no additional cost. ${ }^{3} \mathrm{~A}$ feature of the analysis is our consideration of the effects of the higher marginal cost of teller transactions. ${ }^{4}$

Firms providing ATM services differ based on their number of customers with banking relationships. At the extremes, the network members could be two banks with equal numbers of customers or a large bank with all the customers together with a non-bank ATM provider. The paper

\footnotetext{
${ }^{2}$ According to McAndrews (1998), the interchange fee ranges from $\$ 0.30$ to $\$ 0.60$ per transaction in the U.S.. We abstract from other fees, such as a "switch fee", ranging from $\$ 0.02$ to $\$ 0.15$, which is paid by network members to cover the cost of routing transactions through the network.

${ }^{3}$ Hannan (2001) states that $72.3 \%$ of U.S. banks surveyed in 1999 charged foreign fees for withdrawals at a non-own ATM, while only $6.4 \%$ charged their own customers fees for withdrawals from own ATMs. An exception is the 1995, $\$ 3$ charge set by First Chicago for some teller transactions (see Duclaux, 1995).

${ }^{4}$ Transaction costs vary between $\$ 0.15$ to $\$ 0.50$ for an ATM and $\$ 1$ to $\$ 2$ for a teller (Fasig, 2001).
} 
contrasts these two polar cases so as to explain the conflict of interest in fee setting between a large bank and a non-bank. Conflicts arise because asymmetry in the number of customers causes asymmetry in the extent to which the ATMs of each member firm are shared. If two banks have equal numbers of customers, then each bank has access to the revenues generated by the same number of the other bank's customers, whereas if one of the members is a non-bank, the non-bank gains access to the bank's customers, but there are no "other customers" from whom the bank can collect fees. Such conflicts have relevance for whether large banks would want non-banks as network members. For example, prior to the 1996 ruling by the Canadian Competition Tribunal, the Interac network, which was controlled by large Canadian banks, specifically prohibited membership by nonbanks. $^{5}$

Foreign fees and surcharges are determined at a non-cooperative Nash equilibrium, whereas the joint decision as to the level of the interchange fee is made a prior stage based on Nash bargaining. The state of the law as to whether or not networks can ban surcharging affects the outside option under Nash bargaining. We examine the implications of a move from a ban on surcharging to the surcharging equilibrium and also the question as to the conditions under which members of the network would make a voluntary agreement not to surcharge.

In order to focus on the differing incentives of banks and non-banks towards the interchange fee and surcharging as a network-wide decision, we simplify the analysis by assuming that firms each deploy the same number of ATMs, which are positioned symmetrically around the circle and interleaved so as to maximize customer convenience. Based on related but different models, Massoud and Bernhardt (2002) and McAndrews (2001) both show that banks with a greater number

\footnotetext{
${ }^{5}$ See the draft consent order issued by the Canadian Competition Tribunal (1996).
} 
of ATMs tend to set higher surcharges. ${ }^{6}$ We expect that if our model were extended to incorporate differences in the number of ATMs across banks, similar results would apply. However, since nonbanks do not provide any customers from whom the banks can collect surcharges (or interchange fees), customer base would continue to be the main driving force behind the differing preferences of banks and non-banks towards interchange fees and surcharging at the network-wide level.

We first develop the implications of joint profit maximization for the shared ATM networks. Comparing with the non-cooperative Nash equilibrium in fee setting then yields a striking result. If surcharging is banned and if the interchange fee equals the marginal cost of an ATM transaction, then the foreign fees set non-cooperatively by network members serve to maximize joint network profits. By contrast, surcharging raises the total price (foreign fee plus surcharge) paid by consumers above the joint profit- maximizing level. Interestingly, high consumer prices for ATM services are ameliorated by the higher marginal cost of teller transactions. Banks lower their foreign fee so as to shift customers away from the branch, with the result that total price is reduced at both the surcharging or no-surcharging equilibriums.

Whether the member firms are both banks or a bank and a non-bank, we show that for a given interchange fee, equilibrium levels of foreign fees and surcharges are unaffected. Thus the conflict between banks and non-banks affects outcomes primarily through network-wide decisions as to the interchange fee and surcharging. Not surprisingly, banks raise the foreign fee in response to an increase in the interchange fee so as to offset some of the cost of the interchange fee payment. However, if there is surcharging, then the foreign fee rises and the surcharge falls by an amount equal to the increase in the interchange fee, with no net effect on the total price paid by consumers.

\footnotetext{
${ }^{6}$ Empirically, banks with larger shares of ATMs are more likely to surcharge (see Hannan et al. ,2003).
} 
Supposing surcharging is not allowed, an initially surprising result in the light of common complaints that large banks charge higher fees, is that competition between a bank and a non-bank or a larger bank and a smaller bank as measured by numbers of customers would lead the larger bank to prefer a lower interchange fee. This follows because a bank with more customers makes a net payment of interchange fees to a smaller bank or a non-bank. Correspondingly, the introduction of surcharging leads to a greater gain in revenue for a smaller bank or a non bank, making the larger bank more eager to prevent surcharging. It is noteworthy that whenever a ban on surcharging would reduce the total price of ATM services, then such a ban would also benefit the larger bank.

This suggests that if the law supports a ban on surcharging, then large banks will want to enforce this requirement. However, if network members have the option to surcharge, as is now the case in most developed countries, an agreement between network members is required to prevent surcharges. To achieve such an agreement, we find that banks must be sufficiently similar in size. An example is the recent agreement by a group of large banks to exempt their customers from surcharges while travelling abroad. ${ }^{7}$ However, if a small and large bank agree not to surcharge, this is likely to involve a higher interchange fee and hence a higher foreign fee charged customers than would occur if no-surcharging could simply be imposed. Under most conditions, a non-bank would choose not to be a party to such an agreement. These results suggest that the option to surcharge and the entry of non-banks would lead to widespread surcharging. Recent experience in both the U.S. and Canada supports this prediction ${ }^{8}$.

\footnotetext{
${ }^{7}$ These were Bank of America, Barclays, Deutsche Bank, Scotiabank and Westpac (see Demers, 2001).

${ }^{8}$ Since the 1996 Competition Tribunal ruling, which required Interac to accept non-banks as members, over $33 \%$ of the ATMs in Canada are "white-label" operated by non-banks with high surcharges (see Roseman, 2002). A similar story applies to the U.S.(see U.S. General Accounting Office, 1998).
} 
The telecommunications industry has been a catalyst for the analysis of networks, from Katz and Shapiro (1985) to more recent work by Laffont, Rey and Tirole (1998). Economides and Salop (1992) explore the implications for market prices of the separate or joint sale of complementary components of a good in a variety of settings, including ATM networks. ${ }^{9}$ Matutes and Padilla (1994) develop a spatial model to examine the incentives for banks to make ATM networks compatible when deposit interest rates are used to compete for customers. There are three banks located around a circle, each with one ATM. With the introduction of interchange fees and surcharges (called withdrawal fees), they show that the equilibrium always involves compatible networks. The model of McAndrews (2001) is most similar to ours in that general numbers of ATMs are symmetrically positioned around the circle and three fees (foreign fees, surcharges and interchange fees) are considered. However, the detailed structure of the model differs and the paper addresses different issues, namely the effects of asymmetric numbers of ATMs and competition for customers. In a model in which banks located around a circle invest in ATMs, Donze and Dubec (2003) show that a high interchange fee set jointly by banks can act as a collusive device in raising the fixed fee that customers pay for an account, but there are no foreign fees or surcharges.

Of more direct relevance with respect to the questions we address is Massoud and Bernhardt (2002) who develop a model in which two banks, located on a circle, provide both ATM and inbranch banking services so as to compete for customers. Profit maximization leads banks to provide ATM services at marginal cost for own customers, whereas other consumers pay a surcharge. One of their main results is to show that laws requiring banks not to discriminate between own customers

\footnotetext{
${ }^{9}$ Our case in which the network sets the interchange fee at marginal cost and bans surcharging, but members set foreign fees non-cooperatively is related to 'one-sided joint price setting' as termed by Economides and Salop (1992). However, in their setting, joint network profits are not necessarily maximized.
} 
and customers of the other bank with respect to ATM fees would paradoxically raise ATM prices above the surcharging level. This contrasts with our result that a ban on surcharging would reduce ATM prices. This seeming difference in results can be explained by the fact that Massoud and Bernhardt do not consider foreign fees or interchange fees. Prices fall in our model, because consumers move from paying the sum of the foreign fee and surcharge to simply paying the foreign fee. Prices rise in Massoud and Bernhardt (2002) because in order to gain revenues from the other bank's customers and not discriminate, banks increase the fee charged own customers for use of an own bank ATM to equal the fee charged the other bank's customers.

The issue of self-regulation by ATM networks is also relevant. Self-regulation would give networks the power to restrict members' pricing policies, including the ability to ban surcharging. A main argument for self-regulation, presented by Gilbert (1991) and supported by our analysis, is that delegation of pricing to network members could lead to fees that exceed joint profit-maximizing levels. An opposing argument in Salop (1990) is that self-regulation results in too few ATMs. Indeed, the recent entry of non-banks in both the U.S. and Canada is in part due to the ability to surcharge and has significantly increased the number of ATMs. This argument would suggest that any loss of consumer welfare from surcharging is a short run effect, which would potentially be offset by entry in the long run.

The spatial model of ATM networks is developed in Section 2. Section 3 examines the implications of joint profit maximization and the equilibrium in foreign fees and surcharges is developed in Section 4. Section 5 explores the implications of the higher cost for in-branch teller transactions. Section 6 then examines the conflict between network members in setting the interchange fee and also develops the conditions under which the members of the network would mutually agree not to surcharge. Section 7 contains concluding remarks. 


\section{The model}

\subsection{The order of moves}

Two firms i for $\mathrm{i}=\mathrm{A}, \mathrm{B}$ offer ATM services. Firm A is a bank and firm B may be a nonbank. Banks also offer in-branch banking services through a teller. The ATM transactions are assumed to be withdrawals. In addition to withdrawals, teller transactions allow customers to undertake other banking business such as verifying accounts, exchanging foreign currency or buying certificates of deposit. Consumers hold an account at only one bank i for which they pay a fee, denoted $\mathrm{F}^{\mathrm{i}}$, where $\mathrm{i}=\mathrm{A}, \mathrm{B}$ if firm $\mathrm{B}$ is a bank. The banking package allows customers to make both own-bank ATM and teller transactions at no cost. However, customers must pay the foreign fees and surcharges applying to transactions at other than an own-bank ATM.

Investment in ATMs is assumed to take place prior to the setting of fees within the network. To the extent that the installation of additional ATMs would raise profitability, a full model would include this response in the long run. ${ }^{10}$ However, since we assume general numbers of ATMs (equally distributed across network members), our analysis already encompasses the effects of different overall levels of investment. Also, taking into account the endogenous response of consumers in switching from in-branch tellers to ATMs, we show that greater numbers of ATMs can lead to higher prices for ATM services. Consequently, an expansion in numbers of ATMs may not always solve the problem of excessively high prices.

The model involves two stages of decision. In stage 1, the interchange fee is determined through Nash bargaining by member firms. If there is an agreement not to surcharge, it is made at

\footnotetext{
${ }^{10}$ The high fixed cost of ATM installation, security and maintenance limits the numbers of ATMs. Based on estimation of a structural model, Gowrisankaran and Krainer (2003) argue that the introduction of surcharging results in only a moderate increase in numbers of ATMs and welfare falls.
} 
this stage. Also, each bank sets $\mathrm{F}^{\mathrm{i}}$ and consumers simultaneously choose their bank. In stage 2, foreign fees and surcharges (if allowed) are set simultaneously, leading to a non-cooperative Nash equilibrium.

The choice of the interchange fee in stage 1 reflects the idea that network agreements are harder to change than the transaction fees determined in stage 2. Also, in choosing their bank in stage 1 , consumers see through to the fees set in stage 2 , but banks do not set fees strategically so as to attract customers. ${ }^{11}$ The choice of bank prior to the setting of transaction fees can be justified on the argument that it is costly to change banks (due, for example, to the use of pre-authorized deposits and withdrawals) and that banks change foreign fees and surcharges more often than customers change banks. Also, for the purpose of exploring the role of non-bank ATM providers, strategic competition between banks for customers adds complication and is not the central issue.

For our polar cases of two identical banks or a bank and a non-bank, the distribution of customers is fully determined. Letting $\mathrm{N}^{\mathrm{i}}$ for $\mathrm{i}=\mathrm{A}, \mathrm{B}$, represent the number of customers of bank $i$, if the network consists of two banks that set the same fees, then consumers choose each bank with equal probability, which implies $\mathrm{N}^{\mathrm{A}}=\mathrm{N}^{\mathrm{B}}$. If firm $\mathrm{B}$ is a non-bank, then $\mathrm{N}^{\mathrm{B}}=0$ and bank $\mathrm{A}$ has all the customers. Almost all our results would apply if the analysis were restricted to just these two cases. Nevertheless, it is useful to allow the share of customers to vary exogenously between these two cases so as to consider the possibility that network members are a large and a small bank. There are a number of plausible reasons why numbers of customers could differ across otherwise identical banks. For example, one could imagine that the bank with the smaller customer base is a recent entrant and since it is costly for consumers to change banks, differences in customer base persist over

\footnotetext{
${ }^{11}$ Whether banks actually set prices strategically is not obvious. For example, Prager (2001) suggests that surcharges set by banks with large ATM networks are not effective in attracting customers from small banks.
} 
a long period.

\subsection{Spatial networks of ATMs}

Each firm $\mathrm{i}$ for $\mathrm{i}=\mathrm{A}, \mathrm{B}$ maintains an ATM network, consisting of a general number $\mathrm{M}$ of ATMs evenly spaced around the unit circle. As illustrated in Figure 1, the ATMs of A and B are interleaved so that there are no segments in which two machines of the same firm are next to each other. Since there is a total of $2 \mathrm{M}$ machines, the distance between adjacent $\mathrm{A}$ and $\mathrm{B}$ machines is $\ell$ $\equiv 1 /(2 \mathrm{M})$. If each firm $\mathrm{i}$ has only one ATM, then $\ell=1 / 2$. Each bank $\mathrm{i}$ issues ATM cards that allow customers to make transactions at an ATM or at bank i's branch, which is located at the centre of the circle, equidistant from each point on the circle. For ease of notation, we assume that each customer makes just one transaction per period and hence the number of customers serves as a proxy for the number of transactions. Customers move around the circular market, but in such as way that they are evenly distributed with the same probability of being at any particular location. This has the useful implication that, although customer utility from ATM transactions varies based on location, on average around the circle, customers can be treated as identical.

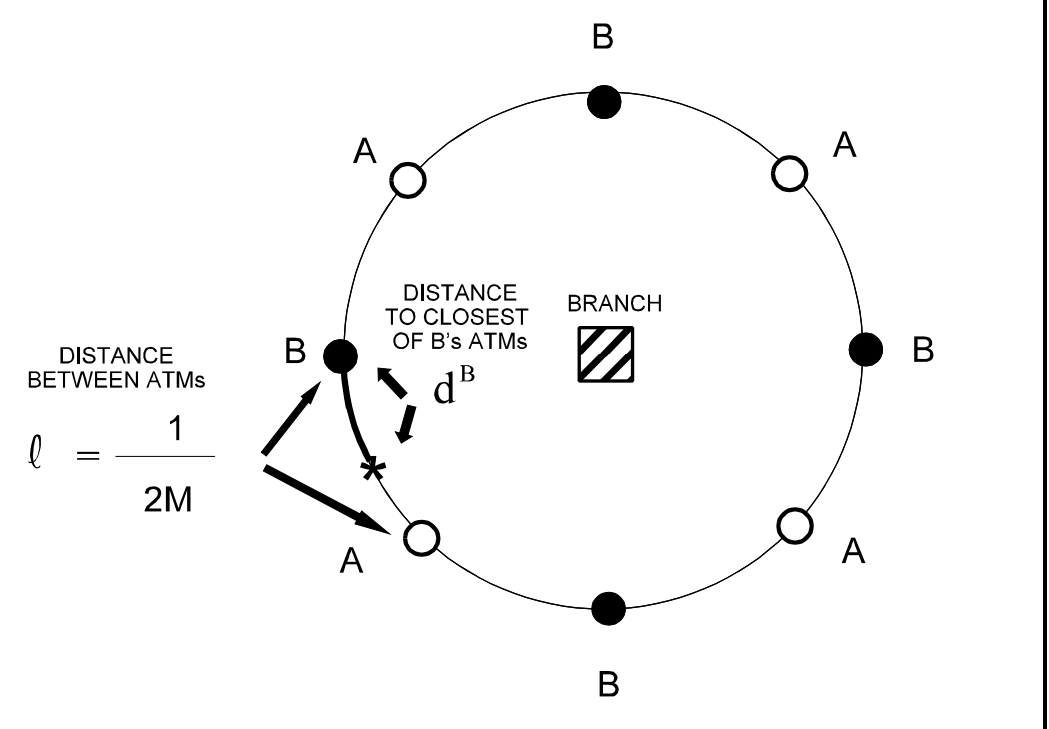

Figure 1. Circular Market for ATM Services. 
Customers of bank i have the option of travelling to the closest of bank i's ATMs, which involves a disutility, denoted $\mathrm{d}^{\mathrm{i}}$, equal to the distance travelled. They also have the option of travelling the distance, $\ell-\mathrm{d}^{\mathrm{i}}$, to a "foreign" ATM of the other firm, but this convenience involves paying the price, $\mathrm{p}^{\mathrm{i}}$, which consists of the sum of the foreign fee and any surcharge. Letting $\mathrm{x}$ denote the utility of an ATM transaction, each customer of bank i gains utility, $u^{\mathrm{H}}\left(\mathrm{d}^{\mathrm{i}}\right)=\mathrm{x}-\mathrm{d}^{\mathrm{i}}$, from use of an own-bank ATM (supercript $\mathrm{H}$ for home) and utility, $\mathrm{u}^{\mathrm{F}}\left(\ell-\mathrm{d}^{\mathrm{i}}\right) \equiv \mathrm{x}-\left(\ell-\mathrm{d}^{\mathrm{i}}\right)-\mathrm{p}^{\mathrm{i}}$ from the use of the other ATM (superscript F for foreign). ${ }^{12}$ Referring to Figure 1, a customer of B can travel d ${ }^{\mathrm{B}}$ to B's ATM and gain $u^{\mathrm{H}}\left(d^{\mathrm{B}}\right)=\mathrm{x}-\mathrm{d}^{\mathrm{B}}$, or travel $\ell-\mathrm{d}^{\mathrm{B}}$ to A's ATM and gain $\mathrm{u}^{\mathrm{F}}\left(\ell-\mathrm{d}^{\mathrm{B}}\right) \equiv \mathrm{x}-\left(\ell-\mathrm{d}^{\mathrm{B}}\right)-\mathrm{p}^{\mathrm{B}}$.

Letting $\mathrm{d}^{\mathrm{i}}=\hat{d}^{i} \in[0, \ell]$, satisfy $\mathrm{u}^{\mathrm{H}}\left(\hat{d}^{i}\right)=\mathrm{u}^{\mathrm{F}}\left(\ell-\hat{d}^{i}\right)$, it follows that customers are indifferent between their own and the closest ATM of the other firm at a distance $\mathrm{d}^{\mathrm{i}}=\hat{d}^{i}$ from their own bank's ATM, where,

$$
\hat{d}^{i}=\left(\ell+\mathrm{p}^{\mathrm{i}}\right) / 2 \text { for } \mathrm{p}^{\mathrm{i}} \in[-\ell, \ell] \text {. }
$$

Consequently, A's customers will prefer A's ATM for $\mathrm{d}^{\mathrm{A}} \leq \hat{d}^{A}$ and will prefer B's ATM for $\mathrm{d}^{\mathrm{A}}$ $>\hat{d}^{A} \cdot{ }^{13}$ We assume $\mathrm{p}^{\mathrm{i}} \in[-\ell, \ell]$. Since $\hat{d}^{i}=\ell$ at $\mathrm{p}^{\mathrm{i}}=\ell$, the price, $\mathrm{p}^{\mathrm{i}}=\ell$ is prohibitive in the sense that customers only use the ATMs of their own bank, making the shared networks no different than two separate unlinked ATM networks. At the other extreme, a subsidy of $p^{i}=-\ell$ would imply no use of own-bank ATMs. Since in practice, moral hazard problems would make transaction subsidies undesirable, the possibility $\mathrm{p}^{\mathrm{i}}<0$ is best interpreted as a price that is below (rather than above) the zero price charged at an own-bank ATM.

For the proportion, $\hat{d}^{i} / \ell$, of bank i's customers located within $\hat{d}^{i}$ of i's machine, the ATMs

\footnotetext{
${ }^{12}$ Units are set so that a one unit increase in $\mathrm{p}^{\mathrm{i}}$ has the same effect on utility as a one unit increase in $\mathrm{d}^{\mathrm{i}}$.

${ }^{13}$ If the utility from A's or B's ATM is equal, we assume a customer will choose an own-bank ATM.
} 
of the other bank offer no extra convenience. On average, these customers have to travel $\mathrm{d}^{\mathrm{i}}=\hat{d}^{i} / 2$ and hence their average utility if they use an ATM is given by $\mathrm{u}^{\mathrm{H}}\left(\hat{d}^{i} / 2\right)=\mathrm{x}-\hat{d}^{i} / 2$. The remaining proportion, $\left(\ell-\hat{d}^{i}\right) / \ell$, of bank i's customers prefer the other firms's ATM, which implies an average utility, $\mathrm{u}^{\mathrm{F}}\left(\left(\ell-\hat{d}^{i}\right) / 2\right)=\mathrm{x}-\left(\ell-\hat{d}^{i}\right) / 2-\mathrm{p}^{\mathrm{i}}$. Combining these two groups to take account of the movement of customers around the circle, each customer of bank i gains an average utility from ATM use, given by $\mathrm{U}^{\mathrm{i}} \equiv\left(\hat{d}^{i} / \ell\right)\left(\mathrm{x}-\hat{d}^{i} / 2\right)+\left(\left(\ell-\hat{d}^{i}\right) / \ell\right)\left(\mathrm{x}-\left(\ell-\hat{d}^{i}\right) / 2-\mathrm{p}^{\mathrm{i}}\right)$. Letting $\gamma\left(\mathrm{p}^{\mathrm{i}}\right) \equiv\left(\ell-\mathrm{p}^{\mathrm{i}}\right)^{2} / 2 \ell$ and using (1) defines $U^{i}=U\left(p^{i}\right)$, where

$$
\mathrm{U}\left(\mathrm{p}^{\mathrm{i}}\right)=\mathrm{x}-\ell / 2+\gamma\left(\mathrm{p}^{\mathrm{i}}\right) / 2
$$

At $\mathrm{p}^{\mathrm{i}}=\ell$, there is no sharing of ATMs and average customer utility from the ATM network is U(l) $=x-\ell / 2$. We assume that $U(\ell)=x-\ell / 2>0$, which implies that $U\left(p^{i}\right)>0$.

The alternative to a withdrawal from an ATM around the circle is for customers to use a teller at their branch (located at the centre of the circle). By using their branch for a withdrawal, customers gain the benefit $\mathrm{x}$, but they also gain utility or value, denoted $\mathrm{v}$, from the ability to do other banking business. We suppose that if a customer makes fewer visits to the branch, then this other banking business accumulates so as to raise $\mathrm{v}$. Letting $\rho^{\mathrm{O}}$ represent the probability of use of the branch, this idea is captured by assuming that $\mathrm{v}$ is decreasing in $\rho^{\mathrm{O}}$. A convenient functional form is

$$
v=\left(1-\rho^{O}\right) / \beta \rho^{\mathrm{O}} \text { for } \beta \geq 0 .
$$

It follows from (3) that $v>0$ for all $\rho^{\mathrm{O}}<1$ and $\mathrm{dv} / \mathrm{d} \rho^{\mathrm{O}}<0$. For any given value of $\rho^{\mathrm{O}}$, a higher value of $\beta$ reduces the value of other banking business at the branch.

Letting $\mathrm{d}^{\mathrm{O}}$ represent the distance to the branch, each customer gains $\mathrm{u}^{\mathrm{O}}$ from the use of a 
teller, where $u^{O} \equiv x-d^{O}+v$. Setting $u^{O}=U\left(p^{i}\right)$ so as to define $v=v\left(p^{i}\right)$, we obtain ${ }^{14}$

$$
v\left(p^{i}\right)=d^{O}-\ell / 2+\gamma\left(p^{i}\right) / 2
$$

where $\gamma\left(p^{i}\right) \equiv\left(\ell-p^{i}\right)^{2} / 2 \ell$. From (3), the probabilities of use of a branch or an ATM are respectively

$$
\rho^{\mathrm{O}}=\rho^{\mathrm{O}}\left(\mathrm{p}^{\mathrm{i}}\right)=1 /\left(1+\beta \mathrm{v}\left(\mathrm{p}^{\mathrm{i}}\right)\right) \text { and } 1-\rho^{\mathrm{O}}\left(\mathrm{p}^{\mathrm{i}}\right)=\beta \mathrm{v}\left(\mathrm{p}^{\mathrm{i}}\right) \rho^{\mathrm{O}}\left(\mathrm{p}^{\mathrm{i}}\right) \text {. }
$$

Thus, from (5), the proportion of transactions at an own bank ATM (rather than the branch) when $\mathrm{p}^{\mathrm{i}}=\ell$ makes access to the other bank's ATMs prohibitively expensive is $\beta \mathrm{v}(\ell)=\left(1-\rho^{\mathrm{O}}(\ell)\right) / \rho^{\mathrm{O}}(\ell)$. For example, if $\beta \mathrm{v}(\ell) \geq 1 / 2$, then at least one third of these transactions are at an own-bank ATM.

To ensure that $\rho^{\mathrm{O}}(\ell)<1$ so that there is some use of own-bank ATMs at $\mathrm{p}^{\mathrm{i}}=\ell$, we require that $\beta \mathrm{v}(\ell)>0$ which implies $\mathrm{v}(\ell)=\mathrm{d}^{\mathrm{O}}-\ell / 2>0$. Thus if each bank has only one ATM (i.e. if $\left.\ell=1 / 2\right)$, then $d^{O}>1 / 4$. To obtain $d^{O}>1 / 4$, we suppose that $d^{O}$ is equal to twice the radius of the unit circle (i.e. $\mathrm{d}^{\mathrm{O}}=1 / \pi=0.3182$ for $\pi=3.146$ ) due to the need to travel both to the branch and back to the city. ${ }^{15}$ We actually assume a slightly stronger condition, namely that

$$
\mathrm{v}(\ell)-\ell=\mathrm{d}^{\mathrm{O}}-3 \ell / 2 \geq 0,
$$

which is used to achieve concavity of profit. Since $\mathrm{d}^{\mathrm{O}}>1 / 4$, we obtain $\mathrm{v}(\ell) \geq \ell$ if $\ell \leq 1 / 6$ due to the bank having at least three ATM's (i.e. $M \geq 3$ ). The condition would hold for all $M \geq 1$ if $d^{O} \geq 3 / 4$.

Taking into account the probability of going to the branch, customers of bank i will use bank i's ATMs with probability $\rho^{\mathrm{H}}=\left(\hat{d}^{i} / \ell\right)\left(1-\rho^{\mathrm{O}}\right)$ and the other firms's ATMs with probability $\rho^{\mathrm{F}}=[(\ell-$ $\left.\left.\hat{d}^{i}\right) / \ell\right]\left(1-\rho^{\mathrm{O}}\right)$. From $(1), \rho^{\mathrm{H}}$ and $\rho^{\mathrm{F}}$ can be expressed for $\mathrm{p}^{\mathrm{i}} \in[-\ell, \ell]$ as

$$
\rho^{\mathrm{H}}\left(\mathrm{p}^{\mathrm{i}}\right)=\left(\ell+\mathrm{p}^{\mathrm{i}}\right)\left(1-\rho^{\mathrm{O}}\right) / 2 \ell, \rho^{\mathrm{F}}\left(\mathrm{p}^{\mathrm{i}}\right)=\left(\ell-\mathrm{p}^{\mathrm{i}}\right)\left(1-\rho^{\mathrm{O}}\right) / 2 \ell .
$$

\footnotetext{
${ }^{14}$ For simplicity, we assume that $\rho^{\mathrm{O}}$ is constant around the circle and hence depends on the average utility, $\mathrm{U}\left(\mathrm{p}^{\mathrm{i}}\right)$, of customers using ATMs. Relaxing this assumption does not change the basic incentives that drive pricing policies, but it significantly complicates the notation and analysis.

${ }^{15}$ The value of $\mathrm{d}^{\mathrm{O}}$ could also be raised by assuming that a withdrawal at the branch (but not at an ATM) involves a cost of waiting in line that is included in $\mathrm{d}^{\mathrm{O}}$. The branch may also be located in a distant suburb.
} 
Since $\rho^{\mathrm{F}}(\ell)=0, \rho^{\mathrm{H}}(\ell)=1-\rho^{\mathrm{O}}(\ell)$ and $\rho^{\mathrm{O}}(\ell)>0$, it follows that at $\mathrm{p}^{\mathrm{i}}=\ell$, customers use only their bank's ATMs and the branch. Correspondingly, since $\rho^{\mathrm{F}}(-\ell)=1-\rho^{\mathrm{O}}(\ell)$ and $\rho^{\mathrm{H}}(-\ell)=0$, a subsidy of $\mathrm{p}^{\mathrm{i}}=-\ell$ leads customers to only use the other firms's ATMs and the branch.

From (5), an increase in the fee, $\mathrm{p}^{\mathrm{i}}$, raises the probability of use of the branch: i.e.

$$
\rho^{\mathrm{O} \prime}\left(\mathrm{p}^{\mathrm{i}}\right)=\beta\left(\rho^{\mathrm{O}}\right)^{2}\left(\ell-\mathrm{p}^{\mathrm{i}}\right) / 2 \ell>0 .
$$

Also, a higher fee reduces the use of the other bank's ATM: i.e from (7) for $\mathrm{p}^{\mathrm{i}} \leq \ell$,

$$
\rho^{\mathrm{F} \prime}\left(\mathrm{p}^{\mathrm{i}}\right)=-\left[1-\rho^{\mathrm{O}}+\left(\ell-\mathrm{p}^{\mathrm{i}}\right) \rho^{\mathrm{O} \prime}\left(\mathrm{p}^{\mathrm{i}}\right)\right] / 2 \ell<0
$$

Customer use of their own bank ATMs is increased: i.e. $\rho^{\mathrm{H} \prime}\left(\mathrm{p}^{\mathrm{i}}\right)>0{ }^{16}$

\section{Joint profit maximization}

This section considers the implications for price of joint profit maximization in stage 2 taking the account fees set in stage 1 as given. Letting $\mathrm{c}^{\mathrm{O}}$ denote the marginal cost of a teller transaction and c the marginal cost of an ATM transaction, the cost advantage from an ATM transaction is represented by $\delta \equiv c^{O}-c \geq 0$. Using $\rho^{\mathrm{H}}=1-\rho^{\mathrm{F}}-\rho^{\mathrm{O}}$, the average cost of ATM and branch transactions per customer is then $c\left(\rho^{\mathrm{H}}+\rho^{\mathrm{F}}\right)+c^{\mathrm{O}} \rho^{\mathrm{O}}=\delta \rho^{\mathrm{O}}+\mathrm{c}$. Each customer of bank i generates an average revenue of $r\left(p^{i}\right) \equiv p^{i} \rho^{F}\left(p^{i}\right)$ in foreign fees and surcharges, which, with account fees included, implies a network profit (across both ATM providers) of $g\left(p^{i}\right)=r\left(p^{i}\right)-\delta \rho^{O}\left(p^{i}\right)-c+F^{i}$. Taking $F^{i}$ set in stage 1 as fixed, the change in overall network profit per customer from an increase in $\mathrm{p}^{\mathrm{i}}$ in stage 2 is given by

$$
\mathrm{g}^{\prime}\left(\mathrm{p}^{\mathrm{i}}\right)=\mathrm{r}^{\prime}\left(\mathrm{p}^{\mathrm{i}}\right)-\delta \rho^{\mathrm{O} \prime}\left(\mathrm{p}^{\mathrm{i}}\right)
$$

where $r^{\prime}\left(p^{i}\right)=\rho^{F}+p^{i} \rho^{F \prime}\left(p^{i}\right)$ represents the effect on network revenue. The term, $\delta \rho^{O \prime}\left(p^{i}\right)$, captures

\footnotetext{
${ }^{16}$ From (7), $\rho^{\mathrm{H} \prime}\left(\mathrm{p}^{\mathrm{i}}\right)=\left[1-\rho^{\mathrm{O}}-\left(\ell+\mathrm{p}^{\mathrm{i}}\right) \rho^{\mathrm{O} \prime}\left(\mathrm{p}^{\mathrm{i}}\right)\right] / 2 \ell$. Using (8) and (5), we obtain $\rho^{\mathrm{H} \prime}\left(\mathrm{p}^{\mathrm{i}}\right)=\beta \rho^{\mathrm{O}}\left[\mathrm{v}\left(\mathrm{p}^{\mathrm{i}}\right)-(\ell / 2) \rho^{\mathrm{O}}\right.$ $\left.+\left(\left(\mathrm{p}^{\mathrm{i}}\right)^{2} / 2 \ell\right) \rho^{\mathrm{O}}\right] / 2 \ell>0$ from $\mathrm{v}\left(\mathrm{p}^{\mathrm{i}}\right) \geq \mathrm{v}(\ell) \geq \ell($ see $(6))$ and $\rho^{\mathrm{O}}\left(\mathrm{p}^{\mathrm{i}}\right)<1$
} 
the increase in cost due to the switching of customers from ATMs to the branch. The interchange fee does not play a role since it is simply a transfer between firms in the network.

Since $\rho^{\mathrm{F}}(\ell)=0$ and $\mathrm{g}(\ell)=-\delta \rho^{\mathrm{O}}(\ell)-\mathrm{c}+\mathrm{F}^{\mathrm{i}}$, the additional profit generated by each customer of bank i from the sharing of ATMs is

$$
g\left(p^{i}\right)-g(\ell)=r\left(p^{i}\right)+\delta\left(\rho^{O}(\ell)-\rho^{O}\left(p^{i}\right)\right)
$$

Letting $\mathrm{p}^{\mathrm{i}}=\ell$ satisfy $\mathrm{g}(\underline{\ell})-\mathrm{g}(\ell)=0$, it follows from (11) that $\underline{\ell}=0$ if $\delta=0$. If $\delta>0$, then we obtain $\underline{\ell}<0$, which implies that the sharing of ATMs can be profitable even if consumers are subsidized to use other than an own-bank ATM. However, since $\delta+\underline{\ell}>0$, the subsidy must be must be less than the cost advantage $\delta .{ }^{17}$ Assuming that $\underline{\ell} \geq-\ell$ to ensure that $p^{i} \in[\underline{\ell}, \ell]$ is within the range $p^{i} \in[-\ell, \ell]$, $\delta$ satisfies $^{18}$

$$
-\underline{\ell} \leq \delta \leq(\mathrm{v}(\ell)+\ell) / \rho^{\mathrm{O}}(\ell)
$$

where $\delta=-2 \underline{\ell} \mathrm{v}(\underline{\ell}) /\left(\ell \underline{\ell} \underline{\ell} \rho^{\mathrm{O}}(\ell)\right.$. As can be seen from (12), the upper bound on $\delta$ is less restrictive when the proportion, $\rho^{\mathrm{O}}(\ell)$, of customers using the branch at $\mathrm{p}^{\mathrm{i}}=\ell$ is small. Since $\mathrm{v}(\ell) \geq \ell$ from (6), we obtain $\delta \leq 2 \mathrm{v}(\ell) / \rho^{\mathrm{O}}(\ell)$, which ensures that $\mathrm{g}^{\prime \prime}\left(\mathrm{p}^{\mathrm{i}}\right)<0$ for $\mathrm{p}^{\mathrm{i}} \in[\underline{\ell}, \ell / 2]$ (see (A7) in the Appendix).

Adding over customers, $\pi^{\mathrm{J}} \equiv \mathrm{N}^{\mathrm{A}} \mathrm{g}\left(\mathrm{p}^{\mathrm{A}}\right)+\mathrm{N}^{\mathrm{B}} \mathrm{g}\left(\mathrm{p}^{\mathrm{B}}\right)$ represents the joint profit (superscript $\mathrm{J}$ for joint) from the ATM networks. Since $g\left(p^{i}\right)$ does not depend on $\mathrm{N}^{\mathrm{A}}$ or $\mathrm{N}^{\mathrm{B}}$, setting $\mathrm{p}^{\mathrm{i}} \in[\underline{\ell}, \ell]$ to maximize $\pi^{\mathrm{J}}$, it follows that the joint profit-maximizing price, denoted $\mathrm{p}^{\mathrm{J}}$, is the same across network members. Proposition 1 sets out some properties of $\mathrm{p}^{\mathrm{J}}$. All proofs of propositions are provided in Appendix A.

Proposition 1: (i)Joint network profits are maximized by charging a price, $p^{J} \in(\underline{\ell}, \ell / 2)$, for use of

\footnotetext{
${ }^{17}$ From $(11)$, we obtain $g\left(p^{\mathrm{i}}\right)-\mathrm{g}(\ell)=\left(\delta+\mathrm{p}^{\mathrm{i}}\right) \rho^{\mathrm{F}}\left(\mathrm{p}^{\mathrm{i}}\right)-\delta\left(\rho^{\mathrm{H}}(\ell)-\rho^{\mathrm{H}}\left(\mathrm{p}^{\mathrm{i}}\right)\right) \geq 0$ only if $\delta+\mathrm{p}^{\mathrm{i}}>0$.

${ }^{18} \mathrm{Using} \rho^{\mathrm{O}}(\ell)-\rho^{\mathrm{O}}\left(\mathrm{p}^{\mathrm{i}}\right)=\beta\left(\mathrm{v}\left(\mathrm{p}^{\mathrm{i}}\right)-\mathrm{v}(\ell)\right) \rho^{\mathrm{O}}\left(\mathrm{p}^{\mathrm{i}}\right) \rho^{\mathrm{O}}(\ell)$ and $\mathrm{v}\left(\mathrm{p}^{\mathrm{i}}\right)-\mathrm{v}(\ell)=\gamma / 2$ from (4) and (5) in (11), (12) follows.
} 
other than an own-bank $A T M$, where $p^{J} \geq 0$ if and only if $\delta \leq v(0) / \rho^{O}(0)$. If $\delta=0$, then $p^{J}>\ell / 3$. (ii) $d p^{J} / d \delta<0$ and $d p^{J} / d \beta>0$. Also, $d p^{J} / d \ell<0$ for $p^{J} \leq 0$.

From Proposition 1(i), joint profit maximization involves $\mathrm{p}^{\mathrm{J}}<\ell / 2$. The gain in profit from a higher price is limited by the ability of customers to shift to the branch or an own-bank ATM. The sign of $\mathrm{p}^{\mathrm{J}}$ depends on the magnitude of $\delta$. More specifically, $\mathrm{p}^{\mathrm{J}} \geq 0$ if and only if $\delta \leq \mathrm{v}(0) / \rho^{\mathrm{O}}$. If there were no cost advantage from ATM use $(\delta=0)$, then $\mathrm{p}^{\mathrm{J}}>\ell / 3$. As set out in Proposition 1(ii), a higher value of $\delta$ reduces $\mathrm{p}^{\mathrm{J}}$. Conversely, a higher value of $\beta$ increases the use of ATMs, which raises $\mathrm{p}^{\mathrm{J}}$. For example, if $\beta \mathrm{v}(\ell)=1 / 2$, which implies that at $p^{\mathrm{i}}=\ell$, one-third of transactions are carried out at own-bank ATMs, then $\mathrm{p}^{\mathrm{J}} \geq 0$ if and only if $\delta \leq(\mathrm{v}(\ell)+\ell / 4)(3 / 2+\ell / 4) .{ }^{19}$ If we also take into account consumer welfare, then since $d U^{i L} / d p^{i}+g^{\prime}\left(p^{i}\right)=-\left(\ell-p^{i}\right) \rho^{O}\left(1+\beta \delta \rho^{O}\right) 2 \ell<0$, maximization of welfare requires $p^{i}=\underline{\ell}$, which implies $p^{i}=0$ at $\delta=0$ and $p^{i}<0$ if $\delta>0$. Since $M$ is taken as given, these welfare results abstract from the costs of investing in ATMs.

Proposition 1(ii) also shows that $\mathrm{dp}^{\mathrm{J}} / \mathrm{d} \ell<0$ for $\mathrm{p}^{\mathrm{J}} \leq 0$. This contrasts with the intuition that an increase in the number, $2 \mathrm{M}$, of ATMs, corresponding to a reduction in the distance, $\ell=1 / 2 \mathrm{M}$, between ATMs, should reduce the price of ATM services, which would imply that $\mathrm{dp} / \mathrm{d} \ell>0$. For $\mathrm{p}^{\mathrm{i}}>0$, a shorter distance increases $\mathrm{p}^{\mathrm{i} / \ell}$, making price more important relative to the distance needed to travel to an own-bank ATM. Thus the proportion, $\rho^{\mathrm{F}}$, of customers using other than their own bank's ATMs would be expected to fall, leading to a fall in price. This tendency is part of the story. However, the greater convenience of ATMs as their numbers increase also causes customers to switch away from in-branch tellers, which tends to increase $\rho^{\mathrm{F}}$ and, at the same time make $\rho^{\mathrm{F}}$ less

\footnotetext{
${ }^{19}$ Since $v(0)=v(\ell)+\ell / 4($ from $(4))$, we obtain $\mathrm{p}^{\mathrm{J}} \geq 0$ iff $\delta \leq \mathrm{v}(0) / \rho^{\mathrm{O}}(0)=(\mathrm{v}(\ell)+\ell / 4)(1+\beta \mathrm{v}(\ell)+\ell / 4)$.
} 
responsive to an increase in price.$^{20}$ These latter effects tend to dominate for $\mathrm{p}^{\mathrm{i} / \ell}$ small with the result that greater numbers of ATMs have an ambiguous effect on price when $p^{J}>0$, but $p^{J}$ actually increases if $\mathrm{p}^{\mathrm{J}} \leq 0$. Since the same opposing effects apply when foreign fees and surcharges are set non-cooperatively, this suggests that an expansion in numbers of ATMs may not always solve the problem of excessively high consumer prices for ATM services.

\section{Foreign fees and surcharges}

We consider three types of fees applying to the use of other than an own-bank ATM, namely foreign fees, surcharges and the interchange fee. This section focusses on the stage 2 non-cooperative Nash equilibrium in foreign fees and surcharges (if allowed). The interchange fee is set in stage 1.

The fees that an ATM provider can charge depend on whether it and the other ATM provider are banks or non-banks. Since firm A is a bank, it can charge its own customers a foreign fee, denoted $\mathrm{f}^{\mathrm{A}}$, for each transaction made at B's ATMs. If firm B is a bank and surcharging is allowed, then bank A will also impose a surcharge, denoted $\sigma^{\mathrm{A}}$, for each transaction by B's customers at A's ATMs. Conversely, bank B will charge its own customers a foreign fee, $\mathrm{f}^{\mathrm{B}}$, for the use of A's ATMs and a surcharge, $\sigma^{\mathrm{B}}$, for transactions by A's customers at B's ATMs. If firm B is a non-bank, then since bank A has all the banking customers, bank A can set a foreign fee (but not a surcharge) and firm B can impose a surcharge (but not a foreign fee) on transactions made by A's customers at B's ATMs. In total, customers of bank A pay a price $\mathrm{p}^{\mathrm{A}}=\mathrm{f}^{\mathrm{A}}+\sigma^{\mathrm{B}}$ and customers of firm $\mathrm{B}$ (if $\mathrm{B}$ is a bank) pay $\mathrm{p}^{\mathrm{B}}=\mathrm{f}^{\mathrm{B}}+\sigma^{\mathrm{A}}$ respectively for a transaction at other than an own-bank ATM. Also, for the same

\footnotetext{
${ }^{20}$ From (5) and (7), $\partial \rho^{\mathrm{O}} / \partial \ell=\left(\beta\left(\rho^{\mathrm{O}}\right)^{2} / 4\right)\left(1+\left(\mathrm{p}^{\mathrm{i} / \ell}\right)^{2}\right)>0$ and $\partial \rho^{\mathrm{F}}\left(\mathrm{p}^{\mathrm{i}}\right) / \partial \ell=\left[-\left(\ell-\mathrm{p}^{\mathrm{i}}\right)\left(\partial \rho^{\mathrm{O}} / \partial \ell\right)+\left(\mathrm{p}^{\mathrm{i} / \ell}\right)\left(1-\rho^{\mathrm{O}}\right)\right] / 2 \ell$ is ambiguous in sign. From (8), (9) and $1-2 \beta \gamma \rho^{\mathrm{O}}=1+\beta(\mathrm{v}(\ell)-3 \gamma / 2)$, we obtain $\partial \rho^{\mathrm{F}}\left(\mathrm{p}^{\mathrm{i}}\right) / \partial \ell=-\rho^{\mathrm{F}}\left(\mathrm{p}^{\mathrm{i}}\right) / \ell+$ $(1+\beta(v(\ell)-3 \gamma / 2))\left(\partial \rho^{\mathrm{O}} / \partial \ell\right)>0$ for $\mathrm{p}^{\mathrm{i}} \geq 0$.
} 
transaction, the network requires that the customer's bank pay an interchange fee, denoted $\tau$, to the other ATM provider so as to compensate for the service.

The net revenue gained by bank A from transactions by its own customers at B's ATMs is given by the difference between its foreign fee, $\mathrm{f}^{\mathrm{A}}$, and $\tau-\mathrm{c}$, which is the excess of the interchange fee over and above the marginal cost of an ATM transaction. If $\mathrm{N}^{\mathrm{B}}>0$, transactions by B's customers at A's ATMs, generate net revenue for bank A equal to $\tau$ - c plus any surcharge, $\sigma^{\mathrm{A}}$. Letting $\mathrm{R}^{\mathrm{A}} \equiv$ $\left(\sigma^{\mathrm{A}}+\tau-\mathrm{c}\right) \rho^{\mathrm{F}}\left(\mathrm{p}^{\mathrm{B}}\right)$ represent the average net revenue that bank A as an ATM owner earns from each of B's customers and using $c \rho^{\mathrm{H}}+\mathrm{c}^{\mathrm{O}} \rho^{\mathrm{O}}=-c \rho^{\mathrm{F}}+\delta \rho^{\mathrm{O}}+\mathrm{c}$, bank A's profits from the ATM network including account fees, $\mathrm{F}^{\mathrm{A}}$, are given by ${ }^{21}$

$$
\pi^{A} \equiv N^{A}\left[\left(f^{A}-(\tau-c)\right) \rho^{F}\left(p^{A}\right)-\delta \rho^{O}\left(p^{A}\right)-c+F^{A}\right]+N^{B} R^{A}
$$

The corresponding expression for firm B is obtained by replacing superscript A with superscript B and recognizing that $\mathrm{N}^{\mathrm{B}}=0$, if $\mathrm{B}$ is a non-bank. Since $\mathrm{g}\left(\mathrm{p}^{\mathrm{i}}\right)=r\left(\mathrm{p}^{\mathrm{i}}\right)-\delta \rho^{\mathrm{O}}\left(\mathrm{p}^{\mathrm{i}}\right)-\mathrm{c}$, it follows that for $\mathrm{i}$ $=\mathrm{A}, \mathrm{B}$,

$$
\pi^{i}=N^{i}\left(g\left(p^{i}\right)-R^{j}\right)+N^{j} R^{i}
$$

If firm $\mathrm{i}$ is a bank (i.e. if $\mathrm{N}^{\mathrm{i}}>0$ ), the first term of (14) represents firm i's profit due the contribution of its own customers to overall network profit less the net revenue, $R^{j} \equiv\left(\sigma^{j}+\tau-c\right) \rho^{F}\left(p^{i}\right)$, that these customers generate for firm $\mathrm{j}$ from the use of firm $\mathrm{j}$ 's ATMs. If firm $\mathrm{j}$ is a bank (i.e. if $\mathrm{N}^{\mathrm{j}}>0$ ), then bank $\mathrm{i}$ also receives net revenue $\mathrm{R}^{\mathrm{j}}$ from the use of its ATMs by $\mathrm{j}$ 's customers.

Foreign fees and surcharges are determined at a non-cooperative Nash equilibrium where we limit the magnitude of $\tau-\mathrm{c}$ by assuming that $\underline{\ell} \leq \tau-\mathrm{c} \leq \ell$ and $\tau \geq 0$. In setting its foreign fee, each bank $i$ chooses $f^{i}$ to maximize $\pi^{i}$ as in (14), taking the price, $p^{j}=f^{j}+\sigma^{i}$ for $j \neq i$ paid by customers

\footnotetext{
${ }^{21}$ Fixed costs of ATMs, such as financing and security, are excluded to reduce notation.
} 
of the other bank as well as $\tau$ and any surcharge, $\sigma^{\mathrm{j}}$, paid by own customers to the other bank as given. Thus, letting $f^{i}=f\left(\tau, \sigma^{j}\right)$ represent the foreign fee where $\sigma^{j}=0$ if there is no surcharging, it follows that at an internal equilibrium, $f^{i}=f\left(\tau, \sigma^{j}\right)$ satisfies the first order condition:

$$
\partial \pi^{i} / \partial f^{i}=N^{i}\left[g^{\prime}\left(p^{i}\right)-\left(\sigma^{j}+\tau-c\right) \rho^{F^{\prime}}\left(p^{i}\right)\right]=0 .
$$

From (15), the foreign fee, denoted $f^{*} \equiv f(\tau, 0)$ in the absence of surcharging, is independent of the customer base and hence banks, whether large or small, charge the same fee for use of other than an own-bank ATM.

With respect to the choice of the surcharge, $\sigma^{\mathrm{j}}$ for $\mathrm{j} \neq \mathrm{i}$, paid by bank i's customers, firm $\mathrm{j}$ (whether a bank or a non-bank) sets $\sigma^{\mathrm{j}}$ to maximize own-profits taking the foreign fee, $\mathrm{f}^{\mathrm{i}}$ set by bank $\mathrm{i}$ and the interchange fee as given. If firm $\mathrm{j}$ is a bank, the fees $\sigma^{\mathrm{i}}$ and $\mathrm{f}^{\mathrm{j}}$ applying to its own banking customers are also taken as given. From (14), the surcharge satisfies the first order condition:

$$
\partial \pi^{\mathrm{j}} / \partial \sigma^{\mathrm{j}}=\mathrm{N}^{\mathrm{i}}\left(\partial \mathrm{R}^{\mathrm{j}} / \partial \sigma^{\mathrm{j}}\right)=\mathrm{N}^{\mathrm{i}}\left[\rho^{\mathrm{F}}\left(\mathrm{p}^{\mathrm{i}}\right)+\left(\sigma^{\mathrm{j}}+\tau-\mathrm{c}\right) \rho^{\mathrm{F}}\left(\mathrm{p}^{\mathrm{i}}\right)\right]=0 .
$$

Letting $\sigma \equiv \sigma\left(\tau, f^{\sigma}\right)$ denote the equilibrium surcharge and $\mathrm{f}^{\sigma} \equiv \mathrm{f}(\tau, \sigma)$ the foreign fee, customers pay a total of $\mathrm{p}^{\sigma} \equiv \mathrm{f}^{\sigma}+\sigma$ for use of other than an own-bank ATM. Foreign fees and surcharges are the same across banks, but the implications for profit depend importantly on differences in customer base. Letting $R^{*} \equiv(\tau-c) \rho^{\mathrm{F}}\left(f^{*}\right)$ and $\mathrm{R}^{\sigma} \equiv(\sigma+\tau-\mathrm{c}) \rho^{\mathrm{F}}\left(\mathrm{p}^{\sigma}\right)$ denote the respective values of the net revenue, $\mathrm{R}^{\mathrm{i}}$, received by firm $\mathrm{i}$ as an ATM owner at the no-surcharging and surcharging equilibriums, it follows from (14) that $\pi^{i}=N^{i} g\left(p^{i}\right)-\left(N^{i}-N^{j}\right) R^{i}$ where $R^{i}=R^{*}$ at $\sigma^{j}=0$ and $R^{i}=R^{\sigma}$ at $\sigma^{j}=\sigma$. If $R^{i}$ $>0$ and $\mathrm{N}^{\mathrm{A}}-\mathrm{N}^{\mathrm{B}}>0$, the greater number of bank A's customers leads to more use of B's ATMs than vice versa and hence to a gain, $\left(N^{A}-N^{B}\right) R^{i}$, by firm $B$ and a loss, $-\left(N^{A}-N^{B}\right) R^{i}$, by bank $A$.

A useful expression is $\mathrm{m}\left(\tau, \sigma^{\mathrm{j}}\right) \equiv \mathrm{f}\left(\tau, \sigma^{\mathrm{j}}\right)-(\tau-\mathrm{c})$, which represents the additional profit to bank i from an own-customer transaction at an ATM of the other firm rather than at an own-bank ATM. If $m=0$, then since $f^{i}-\tau=-c$, the bank is indifferent as to whether its own customers use an 
own ATM at a cost $\mathrm{c}$ or an ATM of the other firm at net cost, $\mathrm{f}^{\mathrm{i}}-\tau$, after receipt of the foreign fee and payment of the interchange fee. If $\sigma^{\mathrm{j}}=0$, then $\mathrm{m}^{*} \equiv \mathrm{m}(\tau, 0)=\mathrm{f}^{*}-(\tau-\mathrm{c})$. Using $(10),(15)$ can be rearranged into the form:

$$
\partial \pi^{\mathrm{i}} / \partial \mathrm{f}^{\mathrm{i}}=\mathrm{N}^{\mathrm{i}}\left[\rho^{\mathrm{F}}\left(\mathrm{p}^{\mathrm{i}}\right)+\mathrm{m} \rho^{\mathrm{F}}\left(\mathrm{p}^{\mathrm{i}}\right)-\delta \rho^{\mathrm{O}}\left(\mathrm{p}^{\mathrm{i}}\right)\right]=0 .
$$

As (17) shows, the foreign fee equates the increase in profit (i.e. $\left.\partial\left(m \rho^{\mathrm{F}}\left(\mathrm{p}^{\mathrm{i}}\right)\right) / \partial \mathrm{f}^{\mathrm{i}}\right)$ that bank i gains due to own-customer use of the other bank's ATMs with the increase in cost from the shifting of customers to the branch.

Now considering the no-surcharging equilibrium, Proposition 2(i) concerns the properties of $\mathrm{f}^{*}$ and $\mathrm{m}^{*}$ and Proposition 2(ii) develops the comparative static effects of changes in the interchange fee.

PROPOSITION 2:(i) If $\tau-c=\ell$, then $f^{*}=\ell$. If $\tau-c<\ell$, then $f^{*} \in(\underline{\ell},(\ell+\tau-c) / 2)$ and

$$
m^{*}=f^{*}-(\tau-c)=(\ell-(\tau-c))\left(v\left(f^{*}\right)-\delta \rho^{o}\left(f^{*}\right)\right) / H\left(f^{*}\right),
$$

where $H\left(f^{*}\right) \equiv 2 v\left(f^{*}\right)-(\delta-\gamma) \rho^{O}>0$. If $\tau=c$, then $m^{*}=f^{*}=p^{J}$. (ii) $f_{\tau}\left(\tau, \sigma^{j}\right)>0$. If $\tau-c<\ell$ and $\delta$ $\leq Q\left(p^{i}\right) / \rho^{o}$ where $Q\left(p^{i}\right) \equiv v\left(p^{i}\right)+\gamma\left(1+\beta v\left(p^{i}\right) \rho^{o}\right)$, then $f_{\tau}<1$ and $m_{\tau}\left(\tau, \sigma^{j}\right)=f_{\tau}-1<0$.

As shown in Proposition 2(i), if $\tau-\mathrm{c}<\ell$, then $\mathrm{f}^{*}$ is at an internal equilibrium with $\mathrm{f}^{*}<\ell$ and the sharing of ATMs, but if $\tau-\mathrm{c}=\ell$, then $\mathrm{f}^{*}=\ell$. The case $\tau=\mathrm{c}$ is particularly interesting. Despite differences in numbers of customers, if the interchange fee just compensates the ATM owner for the marginal cost of ATM use (i.e. if $\tau=c$ ), then the foreign fee, $f^{*}$, obtained non-cooperatively at the Nash equilibrium is equal to $\mathrm{p}^{\mathrm{J}}$ and hence serves to implement the joint profit-maximizing outcome. Since $\mathrm{g}^{\prime}\left(\mathrm{p}^{\mathrm{J}}\right)=0$, it can be seen from $(15)$ that $\mathrm{f}^{*}<\mathrm{p}^{\mathrm{J}}$ for $\tau-\mathrm{c}<0$ and $\mathrm{f}^{*}>\mathrm{p}^{\mathrm{J}}$ for $\tau-\mathrm{c}>0$. Also, from (18), it follows that $\mathrm{m}^{*} \geq 0$ and hence banks gain from their own customer use of the other firm's ATMs rather than own ATMs if and only if $\delta \leq \mathrm{v}\left(\mathrm{f}^{*}\right) / \rho^{\mathrm{O}}\left(\mathrm{f}^{*}\right)$. If $\mathrm{f}^{*}=0$, this is the same as the 
condition for $\mathrm{p}^{\mathrm{J}} \geq 0$ (see Proposition 1(i)).

Proposition 2(ii) shows that $\mathrm{f}^{\mathrm{i}}\left(\tau, \sigma^{\mathrm{j}}\right)$ is increasing in $\tau$, making $\mathrm{f}_{\tau}^{\mathrm{i}}>0$ and hence $\mathrm{f}^{*}{ }_{\tau}>0$ at $\sigma^{\mathrm{j}}$ $=0$. Since banks pay the interchange fee when one of their customers uses another firm's ATM, an increase in $\tau$ leads banks to increase the foreign fee charged own customers, so as to at least partially offset the effect of this transfer on bank revenue. Since $m^{*}>0$ at $\delta=0$, the possibility that the foreign fee is too low to cover the net transfer, $\tau-\mathrm{c}$, arises only if the additional cost, $\delta$, of a teller transaction reduces $\mathrm{f}^{*}$ sufficiently to make $\mathrm{m}^{*}<0$. We are able to show that if $\delta \leq \mathrm{Q}\left(\mathrm{p}^{\mathrm{i}}\right) / \rho^{\mathrm{O}}$, which is less restrictive than the condition $\delta \leq \mathrm{v}\left(\mathrm{p}^{\mathrm{i}}\right) / \rho^{\mathrm{O}}$ required for $\mathrm{m}>0$, then $\mathrm{f}^{\mathrm{i}}\left(\tau, \sigma^{\mathrm{j}}\right)$ increases by less than the increase in $\tau$, making $\mathrm{f}^{*}{ }_{\tau}<1$ and $\mathrm{m}^{*}{ }_{\tau}=\mathrm{f}^{*}{ }_{\tau}-1<0$. Since $\mathrm{p}^{\mathrm{J}}=\mathrm{m}^{*}=\mathrm{f}^{*}=0$ for $\tau-\mathrm{c}=0$, these conditions imply $\mathrm{f}^{*}>0$ and $\mathrm{m}^{*}<0$ for $\tau-\mathrm{c}>0$ and $\mathrm{p}^{\mathrm{J}}=0$. Consequently, $\mathrm{m}^{*}$ tends to be negative if $\tau-\mathrm{c}>0$ and $\mathrm{p}^{\mathrm{J}}$ and $\mathrm{f}^{*}$ are small. If $\mathrm{p}^{\mathrm{J}}>0$ then $\mathrm{m}^{*}=\mathrm{p}^{\mathrm{J}}>0$ at $\tau-\mathrm{c}=0$ and remains positive for 0 $<\tau-\mathrm{c}<\ell$, provided $\mathrm{p}^{\mathrm{J}}$ is sufficiently large.

Next, letting $\pi^{\mathrm{i} \sigma}=\pi^{\mathrm{i}}$ and $\mathrm{m}^{\sigma}=\mathrm{m}(\tau, \sigma)=\mathrm{f}^{\sigma}-(\tau-\mathrm{c})$ at $\sigma^{\mathrm{j}}=\sigma$, Proposition 3 sets out properties of the surcharging equilibrium.

PROPOSITION 3: (i) With surcharging, customers using other than an own-bank ATM pay the fees, $f^{\sigma}$ and $\sigma$, resulting in a price, $p^{\sigma}=f^{\sigma}+\sigma \in(0,2 \ell / 3)$, which strictly exceeds $p^{J}$. If $p^{\sigma} \geq \ell / 2$, then $m^{\sigma}$ $>0$, whereas $m^{\sigma}<0$ if $p^{\sigma} \leq \ell / 3$. If $\delta=0$, then $p^{\sigma}=2 m^{\sigma}>\ell / 2$. If $\delta=0$ and $\tau=c$, then $m^{\sigma}=f^{\sigma}=\sigma$. (ii) $\pi^{i \sigma}, R^{\sigma}$ and $p^{\sigma}$ are independent of $\tau$ : $d f^{\sigma} / d \tau=1, d \sigma / d \tau=-1$ and $d p^{\sigma} / d \tau=d \pi^{i \sigma} / d \tau=0$.

As Proposition 3(i) shows, customers pay a surcharge, leading to an overall price that strictly exceeds the joint profit-maximizing level. In raising its surcharge, each ATM provider ignores the negative effect of a reduction in the sharing of ATMs on the profit of the card issuing bank leading to a loss due to "double marginalization". Since $\mathrm{p}^{\sigma} \in(0,2 \ell / 3)$, it follows that $\mathrm{p}^{\sigma}$ is positive even if 
$\delta$ is sufficient large to make $\mathrm{p}^{\mathrm{J}}<0$. If $\delta=0$, then $\mathrm{p}^{\sigma}=2 \mathrm{~m}^{\sigma}>\ell / 2$, whereas $\mathrm{p}^{\mathrm{J}} \in(\ell / 3, \ell / 2)$. If $\tau=\mathrm{c}$ and $\delta=0$, then $\mathrm{m}^{\sigma}=\mathrm{f}^{\sigma}=\sigma$ and $\mathrm{p}^{\sigma}=2 \mathrm{f}^{\sigma}$. If $\mathrm{p}^{\sigma} \geq \ell / 2$, then $\mathrm{m}^{\sigma}>0$, but we obtain $\mathrm{m}^{\sigma}<0$ if $\delta$ is sufficiently large to make $\mathrm{p}^{\sigma} \leq \ell / 3$.

From Proposition 3(ii), an increase in the interchange fee that banks must pay when own customers use another firms ATMs is fully offset by an equal increase in the foreign fee that customers pay for the service and an equal decrease in the surcharge charged by the ATM owner with the outcome that $\mathrm{p}^{\sigma}$ and profit, $\pi^{\mathrm{i} \sigma}$, are unchanged. Fundamentally, since $\tau$ is a pure transfer within the network, it has no direct effect on customer demand for ATM services and the two instruments, $\mathrm{f}^{\sigma}$ and $\sigma$, fully offset the effect of this transfer on profits and the aggregate price, $\mathrm{p}^{\sigma}$, paid by customers.

It is useful to recognize that $\sigma$ can be positive (a fee) or negative (a subsidy) depending on the value of $\tau$. Letting $\tau=\tau^{\sigma}$ satisfy (16) at $\sigma=0$, then

$$
\tau^{\sigma}-\mathrm{c}=-\rho^{\mathrm{F}}\left(\mathrm{p}^{\sigma}\right) / \rho^{\mathrm{F}}\left(\mathrm{p}^{\sigma}\right)>0
$$

Since $\sigma$ is decreasing in $\tau$, it follows that $\sigma \geq 0$ if $\tau \leq \tau^{\sigma}$ and $\sigma<0$ if $\tau>\tau^{\sigma}$. If $\sigma=0$, then $f^{*}=f^{\sigma}=$ $\mathrm{f}\left(\tau^{\sigma}, 0\right)=\mathrm{p}^{\sigma}$. Also, since $\mathrm{f}^{*}{ }_{\tau}>0$ (from Proposition 2$)$ and $\mathrm{dp} / \mathrm{d} \tau=0$ (from Proposition 3$)$, we obtain

$$
\mathrm{f}^{*} \leq \mathrm{p}^{\sigma} \text { if and only if } \tau \leq \tau^{\sigma} \text {. }
$$

At the surcharging equilibrium, $m^{\sigma}=f^{\sigma}-(\tau-c)$ can be expressed as $m^{\sigma}=p^{\sigma}-(\sigma+\tau-c)$ and from (16), we obtain $\mathrm{r}^{\prime}\left(\mathrm{p}^{\sigma}\right)=\mathrm{m}^{\sigma} \rho^{\mathrm{F}}\left(\mathrm{p}^{\sigma}\right)$. Thus if $\mathrm{m}^{\sigma}>0$, a reduction in $\mathrm{p}^{\mathrm{i}}$ below $\mathrm{p}^{\sigma}$ would raise joint network revenue (i.e. $\mathrm{r}^{\prime}\left(\mathrm{p}^{\sigma}\right)=\rho^{\mathrm{F}}\left(\mathrm{p}^{\sigma}\right)+\mathrm{p}^{\sigma} \rho^{\mathrm{F}}\left(\mathrm{p}^{\sigma}\right)<0$ ) and also reduce costs if $\delta>0$. By contrast, since $\mathrm{r}^{\prime}\left(\mathrm{p}^{\mathrm{J}}\right)=\delta \rho^{\mathrm{O} \prime}\left(\mathrm{p}^{\mathrm{J}}\right) \geq 0($ see $(10))$, joint network revenue is maximized at $\mathrm{p}^{\mathrm{J}}$ if $\delta=0$, and is increasing in $\mathrm{p}^{\mathrm{J}}$ if $\delta>0$. 


\section{ATM fees and the cost of teller transactions}

This section further explores the effects of the additional cost $\delta$ for in-branch teller transactions, including the implications for the account fees, $\mathrm{F}^{\mathrm{i}}$, set in stage 1 .

The requirement that consumers must receive at least non-negative utility to set up a bank account, implies $F^{i} \leq U\left(p^{i}\right)$, where from $(2), U^{\prime}\left(p^{i}\right)=\gamma^{\prime}\left(p^{i}\right) / 2<0$. Since consumers choose their home bank simultaneously with the setting of $\mathrm{F}^{\mathrm{i}}$, each bank maximizes profit taking the number of customers as given, with the outcome that $F^{i}=U\left(p^{i}\right)$ where $p^{i}=f^{*}$ or $p^{i}=p^{\sigma}$. Consequently, whether bank $\mathrm{A}$ is a monopoly bank $\left(\mathrm{N}^{\mathrm{B}}=0\right)$ or there are two banks, banks are able to extract all the consumer surplus from the ATM network.

We show in Proposition 4(i) below that in response to a higher value of $\delta$, banks reduce the foreign fee charged own customers so as to put more emphasis on saving costs by shifting customers away from the branch. Although ATM owners raise their surcharge in response to the decrease in the foreign fee, the overall effect of an increase in $\delta$ is to reduce the price, $\mathrm{f}^{*}$ or $\mathrm{p}^{\sigma}$, paid by customers for use of other than an own-bank ATM. Consequently, holding $\mathrm{F}^{\mathrm{i}}$ fixed, the higher cost of service by in-branch tellers is good for consumers. However, if $\mathrm{F}^{\mathrm{i}}$ is allowed to vary, consumers are indifferent.

Interestingly, the higher costs due to a higher value of $\delta$ are not necessarily bad for profits. Letting $\pi^{i *}$ represent firm i's profit from the ATM network at $\mathrm{p}^{\mathrm{i}}=\mathrm{f}^{*}$, then Proposition 4(ii) shows the expected result that for $F^{i}$ fixed and $\tau=c$, an increase in $\delta$ reduces $\pi^{i *}$ for banks. However, if we assume $\tau-c>0$ making $R^{*}>0$, then the reduction in $\mathrm{f}^{*}$ tends to reduce the distortion arising from $\tau>\mathrm{c}$ and also redistributes profits towards smaller banks and non-banks by increasing the revenue $R^{*}$ received by ATM owners from interchange fees. Consequently, if $\tau>c$, the profits of banks with fewer customers are quite likely to rise and if firm B is a non-bank, its profits certainly rise. Similar 
results apply at the surcharging equilibrium, except that the fall in the foreign fee is partially offset by a rise in $\sigma$, which strengthens the gain of firm B at the expense of bank A. Moreover, taking into account the increase in $\mathrm{F}^{\mathrm{i}}$ due to the improvement in consumer utility as $\mathrm{f}^{*}$ falls, we are not able to rule out the possibility that banks are made better off even at $\tau=\mathrm{c}$.

PRoposition 4: (i) $d f^{*} / d \delta<0 ; d f^{\sigma} / d \delta<0, d \sigma / d \delta>0$ and $d p^{\sigma} / d \delta<0$. (ii) If $N^{i}>0$ and $F^{i}$ fixed, then $d \pi^{*} * d \delta<0$ at $\tau=c$. If $N^{B}=0$, then $d \pi^{B *} / d \delta>0$ for $\tau-c>0$ and $d \pi^{B \sigma} / d \delta>0$.

\section{The interchange fee and agreements not to surcharge}

The fact that joint network profit is reduced by $\tau>c$ or by the introduction of surcharging raises the question as to the incentives underlying the choice of $\tau$ and the conditions under which the ATM providers will agree not to surcharge. This section explores the implications of the differing incentives facing large banks, small banks and stand alone ATM providers with respect to these stage 1 decisions.

Since, $\pi^{\mathrm{i}}=\mathrm{N}^{\mathrm{i}} \mathrm{g}(\ell)$ at $\mathrm{p}^{\mathrm{i}}=\ell($ see $(14))$, letting $\Pi^{\mathrm{i}}\left(\tau, \sigma^{\mathrm{j}}\right)=\pi^{\mathrm{i}}\left(\tau, \sigma^{\mathrm{j}}\right)-\mathrm{N}^{\mathrm{i}} \mathrm{g}(\ell)$ represent firm i's additional profit from the sharing of ATMs within the network, it follows that, with no-surcharging,

$$
\Pi^{i *} \equiv \Pi^{\mathrm{i}}(\tau, 0)=\mathrm{N}^{\mathrm{i}}\left(\mathrm{g}\left(\mathrm{f}^{*}\right)-\mathrm{g}(\ell)\right)-\left(\mathrm{N}^{\mathrm{i}}-\mathrm{N}^{\mathrm{j}}\right) \mathrm{R}^{*}
$$

For the sharing of ATMs, we require $\Pi^{\mathrm{i} *} \geq 0$ for $\mathrm{i}=\mathrm{A}, \mathrm{B}$. It can be shown that $\Pi^{\mathrm{A} *}>0$ for $\mathrm{N}^{\mathrm{A}} \geq \mathrm{N}^{\mathrm{B}}$, but if $\mathrm{R}^{*}<0$ due to $\tau<\mathrm{c}$ and $\mathrm{N}^{\mathrm{A}}>\mathrm{N}^{\mathrm{B}}$, it is possible that $\Pi^{\mathrm{B} *}<0 .{ }^{22}$ We define $\underline{\tau}^{\mathrm{B}}$ to satisfy $\Pi^{\mathrm{B}}\left(\underline{\tau}^{\mathrm{B}}\right.$, $0)=0$. If firm $B$ is a non-bank $\left(N^{B}=0\right)$, then $\pi^{B *}=N^{A} R^{*}$ and $\underline{\tau}^{B}=c$.

\footnotetext{
${ }^{22}$ We obtain $\Pi^{\mathrm{A} *}>0$ for $\tau \in(\underline{\ell}, \ell)$ essentially because $\Pi^{\mathrm{A} *}=\mathrm{R}^{*}=0$ at $\mathrm{f}^{*}=\tau=\ell$ and $\mathrm{d} \Pi^{\mathrm{A} *} / \mathrm{d} \tau<0$.
} 
From $(21)$, and $\partial \pi^{\mathrm{i}} / \partial \mathrm{f}^{\mathrm{i}}=0$ (see (15)), the effect of the interchange fee on profit at $\sigma^{\mathrm{j}}=0$ is ${ }^{23}$

$$
d \pi^{i * / d} \tau=d \Pi^{i * / d} \tau=N^{i}(\tau-c) \rho^{F \prime}\left(f^{*}\right) f_{\tau}-\left(N^{i}-N^{j}\right)(d R * / d \tau)
$$

where $d R^{*} / d \tau=\rho^{\mathrm{F}}\left(f^{*}\right)+(\tau-c) \rho^{\mathrm{F}}\left(\mathrm{f}^{*}\right) \mathrm{f}_{\tau}$. If the banks are the same size (i.e. if $\left.\mathrm{N}^{\mathrm{A}}=\mathrm{N}^{\mathrm{B}}\right)$, then both banks would prefer $\tau=c$, which implements the joint profit-maximizing price, $f^{*}=p^{\mathrm{J}}$. However, since $d R * / d \tau>0$ at $\tau=c,(22)$ shows that if $N^{A}=N^{B}$, bank A gains from a reduction in $\tau$ below $c$ and firm B from an increase in $\tau$ above c. Letting $\tau^{\mathrm{A} *}$ and $\tau^{\mathrm{B} *}$ represent the interchange fee preferred by banks $A$ and $B$ respectively, this implies that $\tau^{\mathrm{A} *} \leq \mathrm{c}$ and $\tau^{\mathrm{B} *} \geq \mathrm{c}$. For a non-bank, $\tau^{\mathrm{B} *}=\tau^{\mathrm{R} *}$ where $\tau^{\mathrm{R} *}$ maximize $\mathrm{R} *$

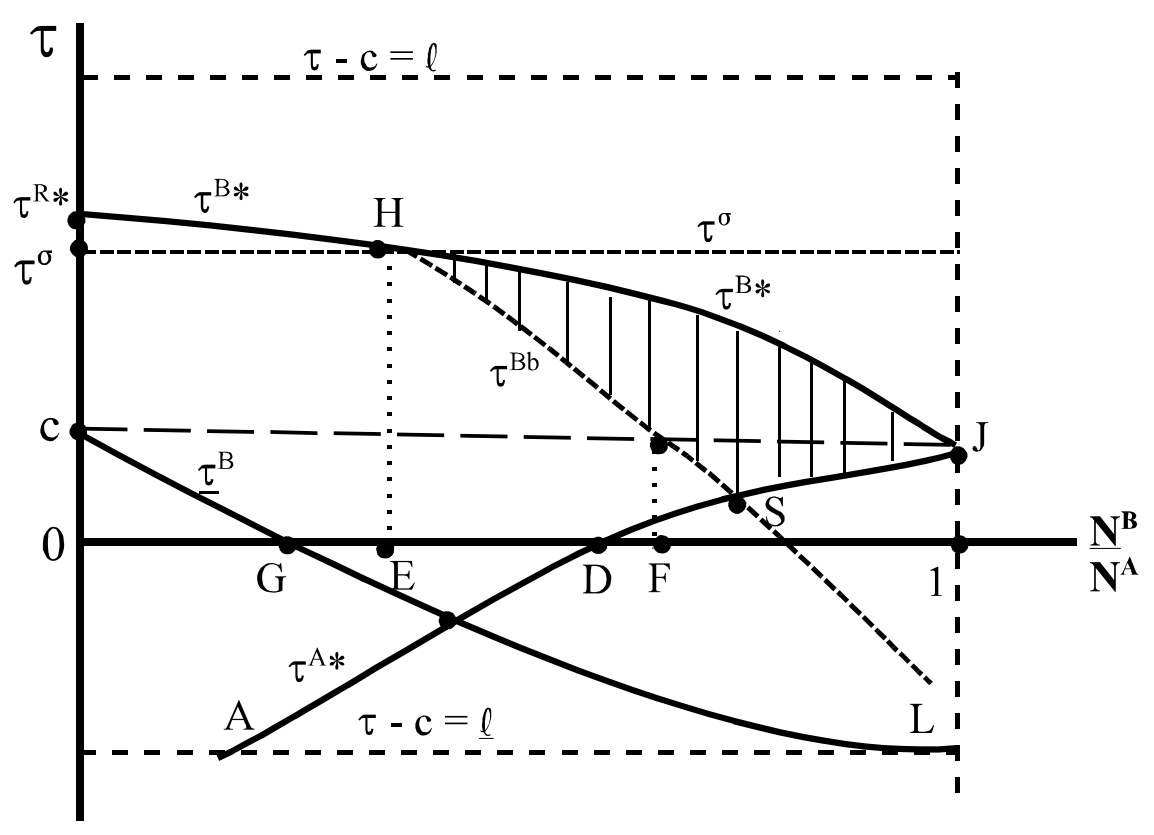

Figure 2: Feasible interchange fees and relative firm size

In Figure 2, the upper and lower limits on the value of $\tau$ are shown by the dashed lines at $\tau$ -

\footnotetext{
${ }^{23}$ We assume $d^{2} \pi^{\mathrm{A} *} /(\mathrm{d} \tau)^{2}=\left(2 \mathrm{~N}^{\mathrm{B}}-\mathrm{N}^{\mathrm{A}}\right) \rho^{\mathrm{F}}\left(\mathrm{f}^{*}\right) \mathrm{f}_{\tau}+\mathrm{N}^{\mathrm{B}}(\tau-\mathrm{c})\left(\rho^{\mathrm{F}}\left(\mathrm{f}^{*}\right)\left(\mathrm{f}_{\tau} *\right)^{2}+\rho^{\mathrm{F}}\left(\mathrm{f}^{*}\right) \mathrm{f}_{\tau \tau}\right)<0$ at $\mathrm{N}^{\mathrm{A}}=\mathrm{N}^{\mathrm{B}}$, which holds if the first term dominates. It follows that $d^{2} \pi^{B} * /(d \tau)^{2}<0$ for $N^{A} \geq N^{B}$ and $d^{2} R^{*} /(d \tau)^{2}=N^{i}\left[2 \rho^{F \prime}\left(f^{*}\right) f_{\tau}\right.$ $\left.+(\tau-c)\left(\rho^{\mathrm{F} \prime \prime}\left(\mathrm{f}^{*}\right)\left(\mathrm{f}_{\tau}^{*}\right)^{2}+\rho^{\mathrm{F}}\left(\mathrm{f}^{*}\right) \mathrm{f}_{\tau \tau}\right)\right]<0$.
} 
$\mathrm{c}=\ell$ and $\tau-\mathrm{c}=\underline{\ell}$ respectively. The solid lines from points $\mathrm{A}$ to $\mathrm{J}$ and $\tau^{\mathrm{R} *}$ to $\mathrm{J}$ respectively trace out the value of these preferred fees as $\mathrm{N}^{\mathrm{B}} / \mathrm{N}^{\mathrm{A}}$ is increased. ${ }^{24}$ As shown in the Figure, $\tau^{\mathrm{A} *}$ is below $\mathrm{c}$ and $\tau^{\mathrm{B} *}$ is above $\mathrm{c}$, but $\tau^{\mathrm{A} *}$ rises and $\tau^{\mathrm{B} *}$ falls as the size of the banks become more equal. If the two banks have the same customer base, then $\tau^{\mathrm{A} *}=\tau^{\mathrm{B} *}=\mathrm{c}$, as shown at point $\mathrm{J}$. As illustrated by the solid line from $\mathrm{c}$ to $\mathrm{L}$, the minimum value of $\tau$ that is compatible with firm B participating in the network declines from $\underline{\tau}^{\mathrm{B}}=\mathrm{c}$ at $\mathrm{N}^{\mathrm{B}}=0$ to $\underline{\mathrm{l}}$ as the banks become similar in size.

Suppose now that firms have the option of surcharging. From (14) and (21), we can express the difference in profit for firm i from no-surcharging relative to surcharging as

$$
\pi^{i *}-\pi^{i \sigma}=N^{i}\left(g\left(f^{*}\right)-g\left(p^{\sigma}\right)\right)+\left(N^{i}-N^{j}\right)\left(R^{\sigma}-R^{*}\right)
$$

where, from (11) and (20), $g\left(f^{*}\right)-g\left(p^{\sigma}\right)=r\left(f^{*}\right)-r\left(p^{\sigma}\right)+\delta\left(\rho^{O}\left(p^{\sigma}\right)-\rho^{O}\left(f^{*}\right)\right)>0$ if $c \leq \tau \leq \tau^{\sigma}$ and $g\left(f^{*}\right)$ $g\left(p^{\sigma}\right)<0$ for $\tau \geq \tau^{\sigma}$. Evaluating (23) at $\tau=\tau^{\sigma}$, since $f^{*}=f\left(\tau^{\sigma}, 0\right)=p^{\sigma}$ and $R^{\sigma}=R^{*}$ at $\sigma=0$, it follows that both $\mathrm{A}$ and $\mathrm{B}$ are indifferent between the no-surcharging and surcharging equilibriums. Assuming $\delta \leq \mathrm{Q}\left(\mathrm{p}^{\sigma}\right) / \rho^{\mathrm{O}}$, which implies $1-\mathrm{f}_{\tau}\left(\tau^{\sigma}, 0\right)>0$, we can show that $\mathrm{R}^{\sigma}-\mathrm{R}^{*}>0$ if $\tau<\tau^{\sigma}$ and $\mathrm{R}^{\sigma}-\mathrm{R} *<0$ if $\tau^{\sigma}<\tau \leq \tau^{\mathrm{R} *}{ }^{25}$ It can then be seen from (23) that the larger bank will strictly prefer nosurcharging for $\mathrm{c} \leq \tau<\tau^{\sigma}$ and surcharging for $\tau^{\sigma}<\tau \leq \tau^{\mathrm{R} *}$. By contrast, the smaller bank faces a tradeoff between the higher joint profit (due to $\mathrm{g}\left(\mathrm{f}^{*}\right)-\mathrm{g}\left(\mathrm{p}^{\sigma}\right)>0$ for $\mathrm{c} \leq \tau<\tau^{\sigma}$ ) under no-surcharging and its gain from surcharging due to $R^{\sigma}-R^{*}>0$ for $\tau<\tau^{\sigma}$.

Whether there is surcharging and the value of the interchange fee in the event of nosurcharging depends importantly on the rights of the parties under the law. We consider two legal

\footnotetext{
${ }^{24}$ If $\mathrm{N}^{\mathrm{B}}=0$ or small, then bank A may prefer $\tau=-\infty$, but values of $\tau-\mathrm{c}<\underline{\ell}$ are not relevant for the analysis. If $\mathrm{N}^{\mathrm{B}}=0$, then since $\mathrm{R}^{*}$ is maximized at some $\mathrm{f}^{*}<\ell$, we obtain $\tau^{\mathrm{B} *}-\mathrm{c}<\ell$.

${ }^{25}$ From $\rho^{\mathrm{F}}\left(\mathrm{f}^{*}\right)+\left(\tau^{\sigma}-\mathrm{c}\right) \rho^{\mathrm{F}}\left(\mathrm{f}^{*}\right)=0$ (see $\left.(16)\right)$ and $1-\mathrm{f}_{\tau}\left(\tau^{\sigma}, 0\right)>0$, we obtain $\mathrm{dR} * / \mathrm{d} \tau=-\left(\tau^{\sigma}-\mathrm{c}\right) \rho^{\mathrm{F}}\left(\mathrm{f}^{*}\right)(1-$ $\left.f_{\tau}^{*}\right)>0$ at $\tau=\tau^{\sigma}$ and hence $\tau^{R *}>\tau^{\sigma}$. The result follows since $R^{\sigma}-R^{*}=0$ at $\tau=\tau^{\sigma}$ and $d^{\sigma} / d \tau=0$.
} 
frameworks. In the first, which was the historical reality in most states in the U.S. until 1996, networks can prevent surcharging as a condition of membership. Within the context of our model, enforcing such a requirement would be in the interests of the larger bank under the reasonable assumption that it has sufficient bargaining power to make $\tau<\tau^{\sigma}$, which includes the possibility that joint profits are maximized at $\tau=c$. In the second legal framework, representing the current situation in the United States and Canada, member banks can mutually agree not to surcharge, but otherwise surcharging cannot be prevented.

Assuming that the interchange fee is determined by generalized Nash bargaining between members of the network, suppose first that there is a law banning surcharging. Each firm then faces the outside option of not sharing its ATMs within the network. Hence if bank A has bargaining power $\alpha \in(0,1)$ and firm B has bargaining power $1-\alpha, \tau$ is determined by maximizing $\left(\Pi^{\mathrm{A} *}\right)^{\alpha}\left(\Pi^{\mathrm{B} *}\right)^{1-}$ ${ }^{\alpha}$. Now suppose that surcharging cannot be banned as a condition of membership. Since firms have the outside option of surcharging, the value of $\tau$ supposing that network members agree not to surcharge is then determined by maximizing $\left(\pi^{\mathrm{A} *}-\pi^{\mathrm{A} \sigma}\right)^{\alpha}\left(\pi^{\mathrm{B} *}-\pi^{\mathrm{B} \sigma}\right)^{1-\alpha}$. For the purposes of Proposition 5 describing the results, we define $\tau=\tau^{\mathrm{Bb}}$ (b for borderline) to satisfy $\pi^{\mathrm{B} *}-\pi^{\mathrm{B} \sigma}=0$ where $\underline{\tau}^{\mathrm{B}}<\tau^{\mathrm{Bb}}<\tau^{\mathrm{B} *}$ and $\tau^{\mathrm{B} *}<\tau^{\sigma}$. As Figure 2 illustrates, $\tau^{\mathrm{Bb}}$ (shown as the dotted line HL) is below $\tau^{\mathrm{B} *}$ (shown as the solid line HJ), which in turn is below the horizontal line representing $\tau^{\sigma}$.

Proposition 5. (i) Whether or not surcharging is an option, if $N^{A}=N^{B}$, both banks agree not to surcharge and set $\tau=c$. (ii) If surcharging is banned, then $\tau \in\left(\max \left[\underline{\tau}^{B}, \tau^{A *}\right], \tau^{B *}\right)$. If $N^{B}=0$, then $\tau \in\left(c, \tau^{B *}\right)$. (iii) If surcharging is allowed and $N^{B} / N^{A}>1-f_{\tau}\left(\tau^{\sigma}, 0\right)$, then Nash bargaining would give rise to a no-surcharging agreement in which $\tau \in\left(\tau^{B b}, \tau^{B *}\right)$ and $\tau>\tau^{A *}$. If $N^{B}=0$ and 1 $f_{\tau}\left(\tau^{\sigma}, 0\right)>0$, then no agreement is possible and surcharging is the outcome. 
It is easily understandable that identical banks would set $\tau=\mathrm{c}$ and agree not to surcharge (as shown in Proposition 5(i)) since (from Proposition 2) such actions maximize joint profits. However, this outcome is not guaranteed if banks differ in the size of their customer base or if a network member is a non-bank. Recalling that for the larger bank, $\tau^{\mathrm{A} *}<\mathrm{c}$ and for the smaller bank, $\tau^{\mathrm{B} *}>$ c, we show in Proposition 5(ii) that when surcharging is banned, the interchange fee can take values between $\tau=\tau^{\mathrm{A} *}$ and $\tau=\tau^{\mathrm{B} *}$, provided the constraint that $\tau>\underline{\tau}^{\mathrm{B}}$ is met. In Figure 2 (assuming $\tau \geq$ 0 ), the region of agreement is illustrated by the area BJDGc. Since for $\tau<\tau^{\mathrm{A} *}$, both banks are better off at $\tau=\tau^{\mathrm{A} *}$ and since for $\tau>\tau^{\mathrm{B} *}$, both banks are better off at $\tau=\tau^{\mathrm{B} *}$, Nash bargaining with $\alpha \in$ $(0,1)$ implies $\tau \in\left(\tau^{\mathrm{A} *}, \tau^{\mathrm{B} *}\right)$. If firm $\mathrm{B}$ is a non-bank, the constraint $\tau>\underline{\tau}^{\mathrm{B}}$ ensures $\tau-\mathrm{c}>0$. However, it remains true that if the banks are not too different in size or if the larger bank has more bargaining power, then, in cases where $\tau-\mathrm{c}>0$, one would expect that the amount by which $\tau$ exceeds c is small. In such a situation, foreign fees would be low, favouring bank customers. Since it is the large banks that have pioneered the development of ATM networks, this case has particular relevance for the United States up until the early 1990's when no-surcharging rules had not been legally challenged.

Now suppose that ATM networks do not prevent surcharging as a condition of membership, but member firms can form voluntary agreements not to surcharge. Exploring the conditions required for an agreement, Proposition 5(iii) shows that $\mathrm{N}^{\mathrm{B}} / \mathrm{N}^{\mathrm{A}}>1-\mathrm{f}_{\tau}\left(\tau^{\sigma}, 0\right)$ (corresponding in Figure 2 to values of $\mathrm{N}^{\mathrm{B}} / \mathrm{N}^{\mathrm{A}}$ to the right of point $\mathrm{E}$ ), provides the dividing line at which the banks are sufficiently similar in size for an agreement to be possible. If $\mathrm{N}^{\mathrm{B}} / \mathrm{N}^{\mathrm{A}}$ is to the left of point $\mathrm{E}$ (which includes nonbanks), then $\mathrm{d} \pi^{\mathrm{B} * / \mathrm{d} \tau}>0$ at $\tau=\tau^{\sigma}$ (satisfying $\pi^{\mathrm{B} *}-\pi^{\mathrm{B} \sigma}=0$ and $\sigma=0$ ), which implies that firm $\mathrm{B}$ prefers surcharging for $\tau<\tau^{\sigma}$ and no surcharging for $\tau^{\sigma}<\tau \leq \tau^{\mathrm{B} *}$. Fundamentally, the higher revenue from surcharging $\left(\mathrm{R}^{\sigma}-\mathrm{R}^{*}>0\right)$ for $\tau<\tau^{\sigma}$ dominates the advantage from higher joint profit 
for $\mathrm{N}^{\mathrm{B}}$ sufficiently small. Since bank A prefers no surcharging only if $\tau<\tau^{\sigma}$, no agreement is possible.

If $\mathrm{N}^{\mathrm{B}} / \mathrm{N}^{\mathrm{A}}>1-\mathrm{f}_{\tau}\left(\tau^{\sigma}, 0\right)$, then $\mathrm{d} \pi^{\mathrm{B} *} / \mathrm{d} \tau<0$ at $\tau=\tau^{\sigma}$ which implies that $\mathrm{B}$ 's preferred interchange fee, $\tau^{\mathrm{B} *}$, is below $\tau^{\sigma}$ and $\pi^{\mathrm{B} *}-\pi^{\mathrm{B} \sigma}>0$ at $\tau=\tau^{\mathrm{B} *}$. Since $\pi^{\mathrm{B} *}-\pi^{\mathrm{B} \sigma}<0$ at $\tau=\underline{\tau}^{\mathrm{B}}$, it follows that $\mathrm{B}$ is indifferent between surcharging and not surcharging (i.e. $\left.\pi^{\mathrm{i} *}-\pi^{\mathrm{i} \sigma}=0\right)$ at some $\tau=\tau^{\mathrm{Bb}}$ where $\underline{\tau}^{\mathrm{B}}<$ $\tau^{\mathrm{Bb}}<\tau^{\mathrm{B} *}$. Consequently, any no-surcharging agreement must involve $\tau>\tau^{\mathrm{Bb}}$ as well as the requirement (from both $\mathrm{A}$ and $\mathrm{B}$ ) that $\tau<\tau^{\sigma}$. The additional requirement from Nash bargaining that $\tau \in\left(\tau^{\mathrm{A} *}, \tau^{\mathrm{B} *}\right)$ further refines the region of potential agreement to the (hatched) area HJS of Figure 2 in which $\tau \in\left(\tau^{\mathrm{Bb}}, \tau^{\mathrm{B} *}\right)$ and $\tau \geq \tau^{\mathrm{A} *}$ as described in Proposition 5(iii). As can be seen from Figure 2, HJS is an area of relatively high fees within the larger region, BJDGc of feasible fees when bank B does not have the option of surcharging.

As a final case, it is interesting to consider the possibility that a network is restricted to setting $\tau-\mathrm{c}=0$, leading to joint profit maximization (i.e. $\mathrm{f}^{*}=\mathrm{p}^{\mathrm{J}}$ ) under no-surcharging. An agreement to give up surcharging is then even more difficult to achieve since a smaller bank is better off by not surcharging at $\tau=\mathrm{c}$ only if $\tau^{\mathrm{Bb}}<\mathrm{c}$. As illustrated in Figure 2 , we have $\tau^{\mathrm{Bb}}<\mathrm{c}$ if $\mathrm{N}^{\mathrm{B}} / \mathrm{N}^{\mathrm{A}}$ is at or to the right of point $\mathrm{F}$.

\section{Concluding Remarks}

This paper focuses on three fees (interchange fee, foreign fee, and surcharge) that apply to the use of ATMs within a spatial model of linked networks. Foreign fees and surcharges are set by banks at a Nash non-cooperative equilibrium, whereas the interchange fee is determined at an earlier stage, based on Nash bargaining. Banks also set a fee for an account at this earlier stage. An initial but important result is to show that if surcharging is ruled out, then an interchange fee equal to the 
marginal cost of an ATM transaction will lead each bank individually to charge a foreign fee that maximizes the joint profits of the shared networks. By contrast, surcharging always raises the total price (the sum of the foreign fee and surcharge) of ATM services above the joint profit-maximizing level. Whether or not there is surcharging, a higher marginal cost for an in-branch teller is shown to reduce the total price charged consumers for transactions at other than own-bank ATMs.

Large banks and non-banks (or small banks) face very different incentives towards both the level of the interchange fee and the decision as to whether surcharging should be allowed in the network. Since a bank with more customers makes net payments of interchange fees, it would prefer a lower interchange fee than a small bank or a non-bank and also no surcharging. In competing with non-banks, banks gain no customers from whom to collect surcharges or interchange fees.

By changing the outside option available to the parties under Nash bargaining, the legal framework with respect to surcharging can have a substantial impact on the level of fees. If nosurcharging is established as a condition of network membership, then both firms face an outside option of forgoing the gains from sharing their ATMs. However, if such a restriction is prohibited, each firm can achieve at least their profit at the surcharging equilibrium. Since the option of surcharging is more valuable to the smaller than the larger bank, consumers tend to lose from such a shift in the law, both due to the increased prevalence of surcharging and the tendency for foreign fees to rise if an agreement is reached not to surcharge. Generally, when surcharging is an option, a greater similarity in size of customer base makes it more likely that the member banks will agree not to surcharge and also keep fees low to the benefit of customers.

Relating these results to the Canadian experience prior to the 1996 ruling by the Canadian Competition Tribunal, the fact that full membership and voting rights were restricted within Interac to the large Canadian banks supports the idea that establishing and maintaining a shared network is 
easier if the customer bases of the network members are comparable in size. Also Interac's prohibition of surcharging together with its refusal to accept non-bank members (prior to 1996) fits with the idea that large banks did not want ATM fees to rise. As shown here, surcharging would raise prices above the joint profit-maximizing level. Also, banks had a motive to keep prices low so as to save costs by reducing the use of in-branch tellers. The Competition Tribunal found that Interac's interchange fees were established collusively. For most goods and services collusive behaviour would be expected to result in excessive prices, with incentives or coercion used to prevent participants from undercutting. The Interac actions seem directly opposite to this expectation. Consistent with our findings, the large charter members maintained downward pressure on fees because of the network benefits they enjoyed. In particular, the $\$ .75$ interchange fee remained unchanged for over 10 years, despite rising charges in other areas.

\section{APPENDIX A}

Proposition 1: (i)Joint network profits are maximized by charging a price, $p^{J} \in(\underline{\ell}, \mathrm{l} / 2)$, for use of other than an own-bank $A T M$, where $p^{J} \geq 0$ if and only if $\delta \leq v(0) / \rho^{O}(0)$. If $\delta=0$, then $p^{J}>\ell$ l3. (ii) $d p^{J} / d \delta<0$ and $d p^{J} / d \beta>0$. Also, $d p^{J} / d \ell<0$ for $p^{J} \leq 0$.

Proof: (i) From (9), (8), $\gamma\left(p^{i}\right) \equiv\left(\ell-p^{i}\right)^{2} / 2 \ell$ and (5), we obtain

$$
\rho^{\mathrm{F}}\left(\mathrm{p}^{\mathrm{i}}\right)=-\left(1-\rho^{\mathrm{O}}+\beta \gamma\left(\rho^{\mathrm{O}}\right)^{2}\right) / 2 \ell=-\beta \rho^{\mathrm{O}}\left(\mathrm{v}\left(\mathrm{p}^{\mathrm{i}}\right)+\gamma \rho^{\mathrm{O}}\right) / 2 \ell .
$$

Letting $\xi^{\mathrm{J}} \equiv \ell-2 \mathrm{p}^{\mathrm{i}}$ and $\omega^{\mathrm{J}} \equiv \delta+\mathrm{p}^{\mathrm{i}}\left(\ell-\mathrm{p}^{\mathrm{i}}\right) / 2 \ell$, it follows from (10) using (7), (8) and (A1) that

$$
g^{\prime}\left(p^{i}\right)=\beta \rho^{O}\left[\xi^{J} v\left(p^{i}\right)-\omega^{J}\left(\ell-p^{i}\right) \rho^{O}\right] / 2 \ell
$$


From $(\mathrm{A} 2)$, we have $\mathrm{g}^{\prime}(\underline{\ell}) \geq \beta \rho^{\mathrm{O}}(\ell-\underline{l})\left(\mathrm{v}(\underline{\ell})-\delta \rho^{\mathrm{O}}(\underline{\ell})\right) / 2 \ell$. Using $\delta=-2 \underline{\ell} \mathrm{v}(\underline{\ell}) /(\ell-\underline{\ell}) \rho^{\mathrm{O}}(\ell)$, we obtain $\mathrm{v}(\underline{\ell})$ $\delta \rho^{\mathrm{O}}(\underline{\ell})=\mathrm{v}(\underline{\ell}) \rho^{\mathrm{O}}(\underline{\ell})\left[(\ell+\underline{\ell})\left(1+\beta \mathrm{v}(\ell)+(\ell-\underline{\ell})(1+\beta \gamma(\underline{\ell}) / 2] /(\ell-\underline{\ell})>0\right.\right.$, which implies $\mathrm{p}^{\mathrm{J}}>\underline{\ell}$. We have $\mathrm{p}^{\mathrm{i}}(\ell-$ $\left.p^{\mathrm{i}}\right) / 2 \ell \geq \underline{\ell}(\ell-\underline{\ell}) / 2 \ell \geq \underline{\ell}$. If $\delta=0$, then $\underline{\ell}=0$ and $\omega^{\mathrm{J}} \equiv \delta+\mathrm{p}^{\mathrm{i}}\left(\ell-\mathrm{p}^{\mathrm{i}}\right) / 2 \ell>0$ for $\mathrm{p}^{\mathrm{i}}>\underline{\ell}$. If $\delta>0$, then (from (12)), $\omega^{\mathrm{J}}>\delta+\underline{\ell}>0$ for $\mathrm{p}^{\mathrm{i}} \in[\underline{\ell}, \ell]$. It then follows from (A2), $\omega^{\mathrm{J}}>0$ and $\xi^{\mathrm{J}}=0$ at $\mathrm{p}^{\mathrm{i}}=\ell / 2$ that $\mathrm{g}^{\prime}(\ell / 2)$ $<0$ and hence $\mathrm{p}^{\mathrm{J}}<\ell / 2$ and $\xi^{\mathrm{J}}>0$ at $\mathrm{p}^{\mathrm{i}}=\mathrm{p}^{\mathrm{J}}$. Since that $\mathrm{g}^{\prime \prime}\left(\mathrm{p}^{\mathrm{i}}\right)<0$ for $\mathrm{p}^{\mathrm{i}} \in[\underline{\ell}, \ell / 2]$ (see (A7)), there is a unique $p^{\mathrm{J}} \in(\underline{\ell}, \ell / 2)$ satisfying $\mathrm{g}^{\prime}\left(\mathrm{p}^{\mathrm{J}}\right)=0$. Since, from $(A 2), \mathrm{g}^{\prime}(0)=\beta \rho^{\mathrm{O}}\left[\mathrm{v}(0)-\delta \rho^{\mathrm{O}}\right] / 2$, we obtain $\mathrm{p}^{\mathrm{J}}$ $\geq 0$ if and only if $\delta \leq v(0) / \rho^{O}$. Setting $\delta=0$ in (A2), we obtain $g^{\prime}\left(p^{J}\right)=\beta \rho^{O}\left[\left(\ell-3 p^{J}\right) v\left(p^{J}\right)+p^{J}\left(v\left(p^{J}\right)-\right.\right.$ $\left.\left.\gamma \rho^{\mathrm{O}}\right)\right]=0$, which implies $\mathrm{p}^{\mathrm{J}}>\ell / 3$ if $\mathrm{v}\left(\mathrm{p}^{\mathrm{i}}\right)-\gamma \rho^{\mathrm{O}}>0$. From $\mathrm{v}\left(\mathrm{p}^{\mathrm{i}}\right)=\mathrm{v}(\ell)+\gamma / 2$ (see (4)), we can show

$$
\mathrm{v}\left(\mathrm{p}^{\mathrm{i}}\right)\left(1+\beta \mathrm{v}\left(\mathrm{p}^{\mathrm{i}}\right)\right)=\mathrm{v}(\ell)(1+\beta \mathrm{v}(\ell))+(\gamma / 2)(1+2 \beta \mathrm{v}(\ell))+\beta(\gamma)^{2} / 4
$$

From (A3), $v(\ell)-\ell>0$ (see (6)) and $\gamma\left(\mathrm{p}^{\mathrm{i}}\right) \leq 2 \ell$ for $\mathrm{p}^{\mathrm{i}} \geq-\ell$, it then follows that

$$
\mathrm{v}\left(\mathrm{p}^{\mathrm{i}}\right)-\gamma \rho^{\mathrm{O}}=\left[(\mathrm{v}(\ell)-\ell)(1+\beta \mathrm{v}(\ell))+\ell-\gamma / 2+\beta \mathrm{v}(\ell)(\ell+\gamma)+\beta(\gamma)^{2} / 4\right] \rho^{\mathrm{O}}>0
$$

(ii) We first show $g^{\prime \prime}\left(p^{i}\right)<0$ for $p^{i} \in[\underline{\ell}, \ell / 2]$. From (8), (A1) and $\gamma \equiv\left(\ell-p^{i}\right)^{2} / 2 \ell$, we obtain

$$
\rho^{\mathrm{O} \prime \prime}\left(\mathrm{p}^{\mathrm{i}}\right)=-\beta\left(\rho^{\mathrm{O}}\right)^{2}\left(1-2 \beta \gamma \rho^{\mathrm{O}}\right) / 2 \ell, \rho^{\mathrm{F} \prime \prime}\left(\mathrm{p}^{\mathrm{i}}\right)=\beta\left(\rho^{\mathrm{O}}\right)^{2}\left(\ell-\mathrm{p}^{\mathrm{i}}\right)\left(3-2 \beta \gamma \rho^{\mathrm{O}}\right) / 4(\ell)^{2} \text {. }
$$

Using $\delta \leq 2 \mathrm{v}(\ell) / \rho^{\mathrm{O}}(\ell)$ (see (12) and (6)), $\mathrm{v}\left(\mathrm{p}^{\mathrm{i}}\right)=\mathrm{v}(\ell)+\gamma / 2$ (see (4)) and $\rho^{\mathrm{O}}(\ell)-\rho^{\mathrm{O}}\left(\mathrm{p}^{\mathrm{i}}\right)=$ $(\beta \gamma / 2) \rho^{\mathrm{O}}\left(\mathrm{p}^{\mathrm{i}}\right) \rho^{\mathrm{O}}(\ell)$, a useful inequality is

$$
2 v\left(p^{i}\right)-\gamma-\delta \rho^{\mathrm{O}}\left(\mathrm{p}^{\mathrm{i}}\right)-(\beta \gamma / 2) \rho^{\mathrm{O}}\left(\mathrm{p}^{\mathrm{i}}\right) \rho^{\mathrm{O}}(\ell)>0
$$

Since $g^{\prime \prime}\left(p^{i}\right)=2 \rho^{F \prime}\left(p^{i}\right)+p^{i} \rho^{F \prime \prime}\left(p^{i}\right)-\delta \rho^{O \prime \prime}\left(p^{i}\right)$ from (10), using (A1) and (A5), we obtain $g^{\prime \prime}\left(p^{i}\right)=-$ $\beta \rho^{\mathrm{O}}\left[2 \mathrm{v}\left(\mathrm{p}^{\mathrm{i}}\right)+\rho^{\mathrm{O}}\left(2 \gamma-3 \mathrm{p}^{\mathrm{i}}\left(\ell-\mathrm{p}^{\mathrm{i}}\right)\right) / 2 \ell-\delta+2 \beta \gamma \rho^{\mathrm{O}} \omega^{\mathrm{J}}\right] / 2 \ell$. Letting $\chi^{\mathrm{J}} \equiv 3\left(\ell-\mathrm{p}^{\mathrm{i}}\right) \xi^{\mathrm{J}} / 2 \ell+2 \beta \gamma \omega^{\mathrm{J}} \rho^{\mathrm{O}}$, since $\chi^{\mathrm{J}}$ $>0$ for $\mathrm{p}^{\mathrm{i}} \in[\underline{\ell}, \ell / 2$ ), it follows using (A6), that

$$
\mathrm{g}^{\prime \prime}\left(\mathrm{p}^{\mathrm{i}}\right)=-\beta \rho^{\mathrm{O}}\left[2 \mathrm{v}\left(\mathrm{p}^{\mathrm{i}}\right)+\rho^{\mathrm{O}}\left(\chi^{\mathrm{J}}-\gamma-\delta\right)\right] / 2 \ell<0
$$

for $\mathrm{p}^{\mathrm{i}} \in[\underline{l}, \ell / 2)$. Now considering the comparative statics, since $\partial^{2} g /\left(\partial \mathrm{p}^{\mathrm{i}}\right)(\partial \delta)=-\beta\left(\rho^{\mathrm{O}}\right)^{2}\left(\ell-\mathrm{p}^{\mathrm{i}}\right) / 2 \ell<0$ and $\partial^{2} \mathrm{~g} /\left(\partial \mathrm{p}^{\mathrm{i}}\right)(\partial \beta)=\beta\left(\rho^{\mathrm{O}}\right)^{2} \xi^{\mathrm{J}}\left(\mathrm{v}\left(\mathrm{p}^{\mathrm{i}}\right)\right)^{2}>0$ evaluated at $\mathrm{g}^{\prime}\left(\mathrm{p}^{\mathrm{i}}\right)=0$, it follows that $\mathrm{dp} / \mathrm{d} \delta<0$ and $\mathrm{dp} / \mathrm{d} \beta$ $>0$. From (A2) and $g^{\prime}\left(p^{J}\right)=0$, we obtain $v\left(p^{J}\right)=\omega^{J}\left(\ell-p^{J}\right) \rho^{O} /\left(\ell-2 p^{J}\right)$ and $v\left(p^{J}\right)-\omega^{J} \rho^{O}=\omega^{J} \rho^{O} p^{J} /(\ell-$ 
$\left.2 p^{\mathrm{J}}\right)$. It then follows from (A2) using $\partial \omega^{\mathrm{J}} / \partial \ell=\left(\mathrm{p}^{\mathrm{i} / \ell}\right)^{2} / 2$ that $\partial \mathrm{g}^{\prime}\left(\mathrm{p}^{\mathrm{J}}\right) / \partial \ell=\beta \rho^{\mathrm{O}}\left[\omega^{\mathrm{J}} \rho^{\mathrm{O}} \mathrm{p}^{\mathrm{J}} /\left(\ell-2 \mathrm{p}^{\mathrm{J}}\right)-(\ell-\right.$ $\left.\left.\left.\mathrm{p}^{\mathrm{J}}\right) \rho^{\mathrm{O}}\left(\mathrm{p}^{\mathrm{i} / \ell}\right)^{2} / 2+\left(\ell-2 \mathrm{p}^{\mathrm{J}}\right)(\partial \mathrm{v} / \partial \ell)-\omega^{\mathrm{J}}\left(\ell-\mathrm{p}^{\mathrm{J}}\right)\left(\partial \rho^{\mathrm{O}} / \partial \ell\right)\right)\right] / 2 \ell$. Since $\partial \mathrm{v} / \partial \ell=-\left(1+\left(\mathrm{p}^{\mathrm{i}} / \ell\right)^{2}\right) / 4<0$ and $\partial \rho^{\mathrm{O}} / \partial \ell$ $=-\beta\left(\rho^{\mathrm{O}}\right)^{2}(\partial \mathrm{v} / \partial \ell)>0$, we obtain $\partial \mathrm{g}^{\prime}\left(\mathrm{p}^{\mathrm{J}}\right) / \partial \ell<0$ for $\mathrm{p}^{\mathrm{J}} \leq 0$.

PROPOSITION 2:(i) If $\tau-c=\ell$, then $f^{*}=\ell$. If $\tau-c<\ell$, then $f^{*} \in(\underline{\ell},(\ell+\tau-c) / 2)$ and

$$
m^{*}=f^{*}-(\tau-c)=(\ell-(\tau-c))\left(v\left(f^{*}\right)-\delta \rho^{o}\left(f^{*}\right)\right) / H\left(f^{*}\right),
$$

where $H\left(f^{*}\right) \equiv 2 v\left(f^{*}\right)-(\delta-\gamma) \rho^{O}>0$. If $\tau=c$, then $m^{*}=f^{*}=p^{J}$. (ii) $f_{\tau}\left(\tau, \sigma^{j}\right)>0$. If $\tau-c<\ell$ and $\delta$ $\leq Q\left(p^{i}\right) / \rho^{O}$ where $Q\left(p^{i}\right) \equiv v\left(p^{i}\right)+\gamma\left(1+\beta v\left(p^{i}\right) \rho^{o}\right)$, then $f_{\tau}<1$ and $m_{\tau}\left(\tau, \sigma^{j}\right)=f_{\tau}-1<0$.

Proof: (i) Specifying the notation so as to also allow for surcharges, we let $\omega \equiv \omega^{\mathrm{J}}-\left(\sigma^{\mathrm{j}}+\tau-c\right)(\ell-$ $\left.p^{\mathrm{i}}\right) / 2 \ell$, which implies $\omega \equiv \delta+\left(\ell-p^{\mathrm{i}}\right) \mathrm{m} / 2 \ell$, where $\mathrm{m} \equiv \mathrm{f}^{\mathrm{i}}-(\tau-\mathrm{c})$. We also let $\xi \equiv \xi^{\mathrm{J}}+\sigma^{\mathrm{j}}+\tau-\mathrm{c}$, which implies $\xi \equiv \ell-p^{i}-m$. From $\partial \pi^{i} / \partial f^{i}=N^{i}\left[g^{\prime}\left(p^{i}\right)-\left(\sigma^{j}+\tau-c\right) \rho^{F^{\prime}}\left(p^{i}\right)\right],(A 1)$ and $(A 2)$, it follows that at an internal equilibrium, $\mathrm{f}^{\mathrm{i}}=\mathrm{f}\left(\tau, \sigma^{\mathrm{j}}\right)$ satisfies the first order condition

$$
\partial \pi^{i} / \partial f^{i}=N^{i} \beta \rho^{O}\left[\xi v\left(p^{i}\right)-\omega\left(\ell-p^{i}\right) \rho^{O}\right] / 2 \ell=0
$$

We show below (see (A10)) that $\partial^{2} \pi^{i} /\left(\partial \mathrm{f}^{\mathrm{i}}\right)^{2}<0$ at $\partial \pi^{\mathrm{i}} / \partial \mathrm{f}^{\mathrm{i}}=0$. Setting $\mathrm{f}^{*}=\mathrm{f}^{\mathrm{i}}(\tau, 0)=\ell$ in (A8), we obtain $\partial \pi^{\mathrm{i}} / \partial \mathrm{f}^{\mathrm{i}}=\mathrm{N}^{\mathrm{i}} \beta \rho^{\mathrm{O}}(\ell-(\tau-\mathrm{c})) \mathrm{v}(\ell) / 2 \ell$, which implies $\mathrm{f}^{*}=\ell$ at $\tau-\mathrm{c}=\ell$ and that $\mathrm{m}^{*}=\mathrm{f}^{*}-(\tau-\mathrm{c})=0$ at $\tau-\mathrm{c}=\ell$. Rearranging (A8), we can show

$$
\partial \pi^{i} / \partial f^{i}=N^{i} \beta \rho^{O}\left[\left(\ell-p^{i}\right)\left(v\left(p^{i}\right)-\delta \rho^{O}\right)-m\left(v\left(p^{i}\right)+\gamma \rho^{O}\right)\right] / 2 \ell=0 .
$$

If $\sigma^{\mathrm{j}} \equiv 0$, then $\mathrm{p}^{\mathrm{i}}=\mathrm{f}^{*}$ and (18) follows from (A9). We have $\mathrm{H}\left(\mathrm{p}^{\mathrm{i}}\right)>0$ from $\delta \leq 2 \mathrm{v}(\ell) / \rho^{\mathrm{O}}(\ell)$. Since $\mathrm{v}(\underline{\ell})$ - $\delta \rho^{\mathrm{O}}(\underline{\ell})>0$ (see proof Proposition $1(\mathrm{i})$ ), evaluating $\partial \pi^{\mathrm{i}} / \partial \mathrm{f}^{\mathrm{i}}$ at $\mathrm{f}^{\mathrm{i}}=\underline{\ell}, \tau-\mathrm{c}=\underline{\ell}$ and $\sigma^{\mathrm{j}}=0$, we obtain $\partial \pi^{\mathrm{i}} / \partial \mathrm{f}^{\mathrm{i}}>0$ and hence $\mathrm{f}^{*}>\underline{\ell}$. It also follows from $\omega \equiv \delta+\mathrm{m}\left(\ell-\mathrm{p}^{\mathrm{i}}\right) / 2 \ell$ and $(\mathrm{A} 9)$ that $\omega=\mathrm{v}\left(\mathrm{p}^{\mathrm{i}}\right)(\gamma+$ $\delta) /\left(v\left(p^{i}\right)+\gamma \rho^{\mathrm{O}}\right)>0$. Hence, if $\tau-\mathrm{c}<\ell$, we obtain $\xi>0$ from $(\mathrm{A} 8)$, which implies $\mathrm{f}^{*}<(\ell+\tau-\mathrm{c}) / 2$. Since $g^{\prime}\left(p^{J}\right)=0$, it follows that $f^{*}=p^{J}$ at $\tau=c$ from (15).

Since $\partial^{2} \pi^{i} /\left(\partial f^{i}\right)^{2}=N^{i}\left[g^{\prime \prime}\left(p^{i}\right)-\left(\sigma^{j}+\tau-c\right) \rho^{F \prime}\left(p^{i}\right)\right] / 2 \ell$ from (15), using (A5) and (A7), we obtain 


$$
\partial^{2} \pi^{i} /\left(\partial f^{i}\right)^{2}=-N^{i} \beta \rho^{O}\left[2 v\left(p^{i}\right)+\rho^{O}(\chi-\gamma-\delta)\right] / 2 \ell
$$

where $\chi \equiv 3\left(\ell-p^{i}\right) \xi / 2 \ell+2 \beta \gamma \omega \rho^{0}$. From (A6), it follows that $\partial^{2} \pi^{i} /\left(\partial \mathrm{f}^{\mathrm{i}}\right)^{2}<0$ if $\chi \geq 0$. Since $\chi=0$ at $\mathrm{p}^{\mathrm{i}}$ $=\ell$, we obtain $\partial^{2} \pi^{\mathrm{i}} /\left(\partial \mathrm{f}^{\mathrm{i}}\right)^{2}<0$ at $\tau-\mathrm{c}=\ell$ and $\mathrm{f}^{*}=\ell$. If $\mathrm{p}^{\mathrm{i}}<\ell$, then $\partial \pi^{\mathrm{i}} / \partial \mathrm{f}^{\mathrm{i}}=0$ implies $\omega>0, \xi>0$ and hence $\chi>0$. Thus $\partial^{2} \pi^{\mathrm{i}} /\left(\partial \mathrm{f}^{\mathrm{i}}\right)^{2}<0$ if $\partial \pi^{\mathrm{i}} / \partial \mathrm{f}^{\mathrm{i}}=0$ or if $\mathrm{p}^{\mathrm{i}}=\ell$.

(ii) Since $\partial^{2} \pi^{\mathrm{i}} /\left(\partial \mathrm{f}^{\mathrm{i}}\right)(\partial \tau)=-\mathrm{N}^{\mathrm{i}} \rho^{\mathrm{F}^{\prime}}\left(\mathrm{p}^{\mathrm{i}}\right)>0($ see $(17))$, we obtain $\mathrm{f}_{\tau}^{\mathrm{i}}\left(\tau, \sigma^{\mathrm{j}}\right)=\mathrm{N}^{\mathrm{i}} \rho^{\mathrm{F}}\left(\mathrm{p}^{\mathrm{i}}\right) /\left(\partial^{2} \pi^{\mathrm{i}} /\left(\partial \mathrm{f}^{\mathrm{i}}\right)^{2}\right)>0$ and

$$
\mathrm{m}_{\tau}=1-\mathrm{f}_{\tau}^{\mathrm{i}}=\left[\partial^{2} \pi^{\mathrm{i}} /\left(\partial \mathrm{f}^{\mathrm{i}}\right)^{2}-\mathrm{N}^{\mathrm{i}} \rho^{\mathrm{F}}\left(\mathrm{p}^{\mathrm{i}}\right)\right] /\left(\partial^{2} \pi^{\mathrm{i}} /\left(\partial \mathrm{f}^{\mathrm{i}}\right)^{2}\right) .
$$

Since $\partial^{2} \pi^{i} /\left(\partial f^{i}\right)^{2}-N^{i} \rho^{F \prime}\left(p^{i}\right)=-N^{i} \beta \rho^{O}\left[v\left(p^{i}\right)+\rho^{O}(\chi-2 \gamma-\delta)\right] / 2 \ell$ from (A1) and (A10), it follows that $\mathrm{m}_{\tau}=1-\mathrm{f}_{\tau}^{\mathrm{i}}\left(\tau, \sigma^{\mathrm{j}}\right)>0$ iff $\mathrm{T} \equiv \mathrm{v}\left(\mathrm{p}^{\mathrm{i}}\right)-\delta \rho^{\mathrm{O}}+\rho^{\mathrm{O}}(\chi-2 \gamma)>0$, where from $\chi \equiv 3\left(\ell-\mathrm{p}^{\mathrm{i}}\right) \xi / 2 \ell+2 \beta \gamma \omega \rho^{\mathrm{O}}$ and (A8), we obtain $\chi=\gamma \xi\left(3+2 \beta v\left(p^{i}\right)\right) /\left(\ell-p^{i}\right)$. Using $\xi=\ell-p^{i}-m$ and substituting for $m$ from (A9), we obtain $\chi-2 \gamma=\gamma \xi\left(1+2 \beta v\left(p^{i}\right)\right) /\left(\ell-p^{i}\right)-2 \gamma\left(v\left(p^{i}\right)-\delta \rho^{O}\right) /\left(v\left(p^{i}\right)+\gamma \rho^{O}\right)$, which implies

$$
\mathrm{T}=\left(\mathrm{v}\left(\mathrm{p}^{\mathrm{i}}\right)-\delta \rho^{\mathrm{O}}\right)\left(\mathrm{v}\left(\mathrm{p}^{\mathrm{i}}\right)-\gamma \rho^{\mathrm{O}}\right) /\left(\mathrm{v}\left(\mathrm{p}^{\mathrm{i}}\right)+\gamma \rho^{\mathrm{O}}\right)+\gamma \rho^{\mathrm{O}} \xi\left(1+2 \beta \mathrm{v}\left(\mathrm{p}^{\mathrm{i}}\right)\right) /\left(\ell-\mathrm{p}^{\mathrm{i}}\right) .
$$

From (A12), $v\left(\mathrm{p}^{\mathrm{i}}\right)-\gamma \rho^{\mathrm{O}}>0($ see $(\mathrm{A} 4)), \xi>0$ and $\omega>0$ at $\mathrm{p}^{\mathrm{i}}$, we obtain $\mathrm{T}>0$ if $\delta \leq \mathrm{v}\left(\mathrm{p}^{\mathrm{i}}\right) / \delta \rho^{\mathrm{O}}$. From (A9) and $\mathrm{p}^{\mathrm{i}}<\ell($ from $\tau-\mathrm{c}<\ell)$, we obtain $\delta \leq \mathrm{v}\left(\mathrm{p}^{\mathrm{i}}\right) / \rho^{\mathrm{O}}$ iff $\mathrm{m} \geq 0$.

Suppose now that $\delta \geq v\left(p^{i}\right) / \rho^{O}$. Using $\rho^{O}=1 /\left(1+\beta v\left(p^{i}\right)\right)$, we obtain $\rho^{O}\left(1+2 \beta v\left(p^{i}\right)\right)=1+$ $\beta v\left(p^{i}\right) \rho^{O}$. Also, from $\xi=\ell-p^{i}-m$ and (A9), we obtain $\xi /\left(\ell-p^{i}\right)=1-\left(v-\delta \rho^{O}\right) /\left(v+\gamma \rho^{O}\right)$. It then follows from $(\mathrm{A} 12)$ that $\mathrm{T}=\left[\left(\mathrm{v}\left(\mathrm{p}^{\mathrm{i}}\right)-\delta \rho^{\mathrm{O}}\right)\left(\mathrm{v}\left(\mathrm{p}^{\mathrm{i}}\right)-2 \gamma\right)+\gamma\left(1+\beta \mathrm{v}\left(\mathrm{p}^{\mathrm{i}}\right) \rho^{\mathrm{O}}\right)\left(\mathrm{v}\left(\mathrm{p}^{\mathrm{i}}\right)+\gamma \rho^{\mathrm{O}}\right)\right] /\left(\mathrm{v}+\gamma \rho^{\mathrm{O}}\right)$. Letting $\mathrm{Q}\left(\mathrm{p}^{\mathrm{i}}\right)$ $\equiv \mathrm{v}\left(\mathrm{p}^{\mathrm{i}}\right)+\gamma\left(1+\beta \mathrm{v}\left(\mathrm{p}^{\mathrm{i}}\right) \rho^{\mathrm{O}}\right)$ we then obtain $\mathrm{T}=\left[\mathrm{v}\left(\mathrm{p}^{\mathrm{i}}\right)\left(\mathrm{Q}\left(\mathrm{p}^{\mathrm{i}}\right)-\delta \rho^{\mathrm{O}}\right)-2 \gamma\left(\mathrm{v}\left(\mathrm{p}^{\mathrm{i}}\right)-\delta \rho^{\mathrm{O}}\right)+(\gamma)^{2} \rho^{\mathrm{O}}(1+\right.$ $\left.\left.\beta v\left(p^{i}\right) \rho^{O}\right)\right] /\left(v+\gamma \rho^{O}\right)>0$ for $v\left(p^{i}\right) / \rho^{O} \leq \delta \leq Q\left(p^{i}\right) / \rho^{O}$. Since $T>0$ for $\delta \leq v\left(p^{i}\right) / \rho^{O}$, this proves $T>0$ and $\mathrm{m}_{\tau}=1-\mathrm{f}_{\tau}^{\mathrm{i}}\left(\tau, \sigma^{\mathrm{j}}\right)>0$ for $\delta \leq \mathrm{Q}\left(\mathrm{p}^{\mathrm{i}}\right) / \rho^{\mathrm{O}}$.

PROPOSITION 3: (i) With surcharging, customers using other than an own-bank ATM pay the fees, $f^{\sigma}$ and $\sigma$, resulting in a price, $p^{\sigma}=f^{\sigma}+\sigma \in(0,2 \ell / 3)$, which strictly exceeds $p^{J}$. If $p^{\sigma} \geq \ell / 2$, then $m^{\sigma}$ $>0$, whereas $m^{\sigma}<0$ if $p^{\sigma} \leq \ell / 3$. If $\delta=0$, then $p^{\sigma}=2 m^{\sigma}>\ell / 2$. If $\delta=0$ and $\tau=c$, then $m^{\sigma}=f^{\sigma}=\sigma$. 
(ii) $\pi^{i \sigma}, R^{\sigma}$ and $p^{\sigma}$ are independent of $\tau$ : $d f^{\sigma} / d \tau=1, d \sigma / d \tau=-1$ and $d p^{\sigma} / d \tau=d \pi^{i \sigma} / d \tau=0$.

Proof: (i) Setting $\partial \pi^{\mathrm{j}} / \partial \sigma^{\mathrm{j}}=0$, it follows from (16), using (5), (7) and (A1), that $\sigma^{\mathrm{j}}=\sigma$ satisfies

$$
\sigma+\tau-\mathrm{c}=-\rho^{\mathrm{F}}\left(\mathrm{p}^{\sigma}\right) / \rho^{\mathrm{F}}\left(\mathrm{p}^{\sigma}\right)=\mathrm{v}\left(\mathrm{p}^{\sigma}\right)\left(\ell-\mathrm{p}^{\sigma}\right) /\left(\mathrm{v}\left(\mathrm{p}^{\sigma}\right)+\gamma \rho^{\mathrm{O}}\right)>0
$$

Since $\partial \pi^{\mathrm{j}} / \partial \sigma^{\mathrm{j}}=0$ implies $\partial \pi^{\mathrm{i}} / \partial \mathrm{f}^{\mathrm{i}}=\mathrm{N}^{\mathrm{i}}\left[\mathrm{g}^{\prime}\left(\mathrm{p}^{\sigma}\right)+\rho^{\mathrm{F}}\left(\mathrm{p}^{\sigma}\right)\right]=0$ (see (15) and (16)) and $\mathrm{g}^{\prime}\left(\mathrm{p}^{\mathrm{J}}\right)=0$, we obtain $\mathrm{p}^{\sigma}>\mathrm{p}^{\mathrm{J}}$ and $\mathrm{p}^{\sigma}$ independent of $\tau$. Also, from (A9) and (A13), we obtain

$$
\partial \pi^{i} / \partial f^{i}=N^{i} \beta \rho^{O}\left[\left(\ell-p^{\sigma}\right)\left(2 v-\delta \rho^{O}\right)-p^{\sigma}\left(v+\gamma \rho^{O}\right)\right] / 2 \ell=0,
$$

which, using (A6), implies $\mathrm{p}^{\sigma}>0$. The second order and stability conditions for the choice of $\sigma$ and $\mathrm{f}^{\sigma}$ are satisfied locally (see part (ii) below).

Rearranging (A14) using $\omega^{\mathrm{J}}\left(\ell-\mathrm{p}^{\mathrm{i}}\right)=\delta\left(\ell-\mathrm{p}^{\mathrm{i}}\right)+\mathrm{p}^{\mathrm{i}} \gamma$, we obtain $\partial \pi^{\mathrm{i}} / \partial \mathrm{f}^{\mathrm{i}}=\mathrm{N}^{\mathrm{i}} \beta \rho^{\mathrm{O}}\left[\left(2 \ell-3 \mathrm{p}^{\sigma}\right) \mathrm{v}-\right.$ $\left.\omega^{\mathrm{J}}\left(\ell-\mathrm{p}^{\sigma}\right) \rho^{\mathrm{O}}\right] / 2 \ell=0$ where $\omega^{\mathrm{J}}=\delta+\mathrm{p}^{\mathrm{i}}\left(\ell-\mathrm{p}^{\mathrm{i}}\right) / 2 \ell>0$ from the proof of Proposition 1 and hence $\mathrm{p}^{\sigma}<$ 2l/3. A further rearrangement of (A14), reveals $\partial \pi^{i} / \partial \mathrm{f}^{\mathrm{i}}=\mathrm{N}^{\mathrm{i}} \beta \rho^{\mathrm{O}}\left[\left(\ell-\mathrm{p}^{\sigma}\right)\left(\mathrm{v}-\delta \rho^{\mathrm{O}}\right)+\mathrm{v}\left(\ell-2 \mathrm{p}^{\sigma}\right)-\right.$ $\left.\mathrm{p}^{\sigma} \gamma \rho^{\mathrm{O}}\right] / 2=0$, which implies that if $\mathrm{p}^{\sigma} \geq \ell / 2$, then $\mathrm{v}-\delta \rho^{O}>0$ and hence $\mathrm{m}^{\sigma}>0$ from (A9). Now adding and subtracting $\mathrm{p}^{\sigma}\left(2 \mathrm{v}-\delta \rho^{\mathrm{O}}\right)$, we obtain $\left(\ell-3 \mathrm{p}^{\sigma}\right)\left(2 \mathrm{v}-\delta \rho^{\mathrm{O}}\right)+\mathrm{p}^{\sigma}\left(3 \mathrm{v}-(\gamma+2 \delta) \rho^{\mathrm{O}}\right)=0$, which implies $p^{\sigma} \geq \ell / 3$ if and only if $3 v-(\gamma+2 \delta) \rho^{O} \geq 0$. Since $3 v-(\gamma+2 \delta) \rho^{O}=2\left(v-\delta \rho^{O}\right)+v-\gamma \rho^{O}$ and $v-$ $\gamma \rho^{O}>0$ from (A4), it follows that $\mathrm{p}^{\sigma} \leq \ell / 3$ only if $\mathrm{v}-\delta \rho^{0}<0$, which requires $\mathrm{m}^{\sigma}<0$ from (A9). If $\delta=0$, then comparing (A13), (A9) and (A14), we obtain $\sigma+\tau-c=m^{\sigma}=f^{\sigma}-(\tau-c)$ and $p^{\sigma}=2 m^{\sigma}$. From (A14), we also obtain $\left(\ell-2 p^{\sigma}\right)\left(2 v-\delta \rho^{O}\right)+p^{\sigma}\left(v-(\gamma+\delta) \rho^{O}\right)=0$, which, since $v-\gamma \rho^{O}>0$ from (A4), implies that $\mathrm{p}^{\sigma}>\ell / 2$ at $\delta=0$.

(ii) For the effects of $\tau$, we first use (6), (A3) and $\ell-3 \gamma / 2>0$ (from $\mathrm{p}^{\sigma}>0$ and $\gamma(0)=\ell / 2$ ) to show

$$
\mathrm{v}-2 \gamma \rho^{\mathrm{O}}=[(\mathrm{v}(\ell)-\ell)(1+\beta \mathrm{v}(\ell))+\ell-3 \gamma / 2+\beta \mathrm{v}(\ell)(\ell+\gamma)] \rho^{\mathrm{O}}>0 .
$$

Since (from (16) and (A13)), $\partial^{2} \pi^{j} /\left(\partial \sigma^{j}\right)\left(\partial f^{i}\right)=N^{A}\left[\left(\rho^{F \prime}\left(p^{i}\right)\right)^{2}-\rho^{F}\left(p^{i}\right) \rho^{F / \prime}\left(p^{i}\right)\right] / \rho^{F \prime}\left(p^{i}\right)$, it follows, using (A1), (A5), (5) and (A15) that $\partial^{2} \pi^{\mathrm{j}} /\left(\partial \sigma^{\mathrm{j}}\right)\left(\partial \mathrm{f}^{\mathrm{i}}\right)=-\mathrm{N}^{\mathrm{i}} \beta \rho^{\mathrm{O}}\left[\mathrm{v}-2 \gamma \rho^{\mathrm{O}}+\left(\gamma \rho^{\mathrm{O}}\right)^{2}(3+2 \beta \mathrm{v}) /\left(\mathrm{v}+\gamma \rho^{\mathrm{O}}\right)\right] / 2 \ell<0$. 
Since $\partial^{2} \pi^{\mathrm{j}} /\left(\partial \sigma^{\mathrm{j}}\right)^{2}=\partial^{2} \pi^{\mathrm{j}} /\left(\partial \sigma^{\mathrm{j}}\right)\left(\partial \mathrm{f}^{\mathrm{i}}\right)+\mathrm{N}^{\mathrm{i}} \rho^{\mathrm{F}}\left(\mathrm{p}^{\mathrm{i}}\right)$ from $(16)$, we obtain $\partial^{2} \pi^{\mathrm{j}} /\left(\partial \sigma^{\mathrm{j}}\right)^{2}<0$ and $\sigma_{\mathrm{f}}\left(\tau, \mathrm{f}^{\sigma}\right)=-$ $\left(\partial^{2} \pi^{\mathrm{j}} /\left(\partial \sigma^{\mathrm{j}}\right)\left(\partial \mathrm{f}^{\mathrm{i}}\right)\right) /\left(\partial^{2} \pi^{\mathrm{j}} /\left(\partial \sigma^{\mathrm{j}}\right)^{2}\right)<0$. Since $\sigma_{\tau} \equiv \sigma_{\tau}\left(\tau, \mathrm{f}^{\sigma}\right)=-\mathrm{N}^{\mathrm{i}} \rho^{\mathrm{F}}\left(\mathrm{p}^{\mathrm{i}}\right) /\left(\partial^{2} \pi^{\mathrm{j}} /\left(\partial \sigma^{\mathrm{j}}\right)^{2}\right)<0$ from (16), it also follows that

$$
\sigma_{\mathrm{f}}\left(\tau, \mathrm{f}^{\mathrm{\sigma}}\right) \equiv \sigma_{\mathrm{f}}=-\left(1+\sigma_{\tau}\right)<0 \text { and }-1<\sigma_{\tau}<0 \text {. }
$$

Using $\partial^{2} \pi^{i} /\left(\partial f^{i}\right)^{2}=\partial^{2} \pi^{i} /\left(\partial f^{i}\right)\left(\partial \sigma^{j}\right)+N^{i} \rho^{F \prime}\left(p^{i}\right)$ from (15), (A11) and $m_{\tau}=1-f_{\tau}^{i}>0$ for $\delta \leq Q\left(p^{i}\right) / \rho^{O}$, we obtain

$$
\mathrm{f}_{\sigma}(\tau, \sigma) \equiv \mathrm{f}_{\sigma}^{\sigma}=\mathrm{f}_{\tau}^{\sigma}-1<0 \text { if } \delta \leq \mathrm{Q}\left(\mathrm{p}^{\mathrm{i}}\right) / \rho^{\mathrm{O}}
$$

Since $\sigma_{\tau}<0$ and $\mathrm{f}_{\tau}^{\sigma}>0$, it follows from (A16) and (A17) that $\sigma_{\mathrm{f}}>-1$ and $\mathrm{f}_{\sigma}^{\sigma}>-1$ and hence

$$
1-\mathrm{f}_{\sigma}^{\sigma} \sigma_{\mathrm{f}}>0
$$

which implies the stability condition, $D \equiv\left(\partial^{2} \pi^{i} /\left(\partial f^{i}\right)^{2}\right)\left(\partial^{2} \pi^{j} /\left(\partial \sigma^{j}\right)^{2}\right)-\left(\partial^{2} \pi^{i} /\left(\partial f^{i}\right)\left(\partial \sigma^{j}\right)\right)\left(\partial^{2} \pi^{j} /\left(\partial \sigma^{j}\right)\left(\partial f^{i}\right)\right)$ $>0$. Since $\mathrm{df}^{\sigma} / \mathrm{d} \tau=\mathrm{f}^{\sigma}{ }_{\tau}+\mathrm{f}^{\sigma}{ }_{\sigma}(\mathrm{d} \sigma / \mathrm{d} \tau)$ and $\mathrm{d} \sigma / \mathrm{d} \tau=\sigma_{\tau}+\sigma_{\mathrm{f}} \mathrm{df} / \mathrm{d} \tau$, we obtain $\mathrm{df}^{\sigma} / \mathrm{d} \tau=\left(\mathrm{f}^{\sigma}{ }_{\tau}+\mathrm{f}^{\sigma}{ }_{\sigma} \sigma_{\tau}\right) /(1-$ $\left.\mathrm{f}^{\sigma}{ }_{\sigma} \sigma_{\mathrm{f}}\right)$ and $\mathrm{d} \sigma / \mathrm{d} \tau=\left(\sigma_{\tau}+\sigma_{\mathrm{f}} \mathrm{f}^{\sigma}{ }_{\tau}\right) /\left(1-\mathrm{f}^{\sigma}{ }_{\sigma} \sigma_{\mathrm{f}}\right)$. Using (A16) and (A17), this implies df $/ \mathrm{d} \tau=1, \mathrm{~d} \sigma / \mathrm{d} \tau=-1$ and $\mathrm{dp}^{\sigma} / \mathrm{d} \tau=0$.

Proposition 4: (i) $d f^{*} / d \delta<0 ; d f^{\sigma} / d \delta<0, d \sigma / d \delta>0$ and $d p^{\sigma} / d \delta<0$. (ii) If $N^{i}>0$ and $F^{i}$ fixed, then $d \pi^{i} * / d \delta<0$ at $\tau=c$. If $N^{B}=0$, then $d \pi^{B *} / d \delta>0$ for $\tau-c>0$ and $d \pi^{B \sigma} / d \delta>0$.

Proof: (i) Since $\partial^{2} \pi^{i} /\left(\partial f^{i}\right)(\partial \delta)=-N^{i} \rho^{O \prime}\left(p^{i}\right)$ from $(17)$, we obtain $\partial f^{i}\left(\tau, \sigma^{j}\right) / \partial \delta=N^{i} \rho^{0 \prime}\left(p^{i}\right) /\left(\partial^{2} \pi^{i} /\left(\partial f^{i}\right)^{2}\right)$ $<0$ and hence $\mathrm{df} * / \mathrm{d} \delta<0$ and $\partial \mathrm{f}^{\mathrm{\sigma}} / \partial \delta<0$. Since $\partial^{2} \pi^{\mathrm{j}} /\left(\partial \sigma^{\mathrm{j}}\right)(\partial \delta)=0$ (see $\left.(16)\right)$ implies $\mathrm{d} \sigma\left(\tau, \mathrm{f}^{\sigma}\right) / \mathrm{d} \delta=$ $\sigma_{\mathrm{f}}\left(\mathrm{df}^{\sigma} / \mathrm{d} \delta\right)$, it follows, using $\mathrm{df}^{\sigma} / \mathrm{d} \delta=\partial \mathrm{f}^{\sigma} / \partial \delta+\mathrm{f}_{\sigma}(\mathrm{d} \sigma / \mathrm{d} \delta)$ and $(\mathrm{A} 18)$, that $\mathrm{df}^{\sigma} / \mathrm{d} \delta=\left(\partial \mathrm{f}^{\sigma} / \partial \delta\right) /\left(1-\sigma_{\mathrm{f}^{\mathrm{f}}} \mathrm{f}_{\sigma}\right)$ $<0$ and, from (A16), that $\mathrm{d} \sigma / \mathrm{d} \delta>0$. Also $\mathrm{dp}^{\sigma} / \mathrm{d} \delta=\left(1+\sigma_{\mathrm{f}}\right)\left(\mathrm{df}^{\sigma} / \mathrm{d} \delta\right)<0$ from (A16). (ii) From (14), $\partial \pi^{\mathrm{i}} / \partial \delta=-\mathrm{N}^{\mathrm{i}} \rho^{\mathrm{O}}\left(\mathrm{p}^{\mathrm{i}}\right)($ see $(11)), \partial \pi^{\mathrm{i}} / \partial \mathrm{f}^{\mathrm{i}}=0($ see $(15))$ and $\mathrm{F}^{\mathrm{i}}$ fixed, we obtain $\mathrm{d} \pi^{\mathrm{i} *} / \mathrm{d} \delta=-\mathrm{N}^{\mathrm{i}} \rho^{\mathrm{O}}\left(\mathrm{f}^{*}\right)+$ $\mathrm{N}^{\mathrm{j}}(\tau-\mathrm{c}) \rho^{\mathrm{F} \prime}\left(\mathrm{f}^{*}\right)(\mathrm{df} * / \mathrm{d} \delta)<0$ for $\mathrm{N}^{\mathrm{i}}>0$ and $\tau=\mathrm{c}$. If $\mathrm{N}^{\mathrm{B}}=0$, then $\mathrm{d} \pi^{\mathrm{B} * / \mathrm{d} \delta}=\mathrm{N}^{\mathrm{A}}(\tau-\mathrm{c}) \rho^{\mathrm{F}}\left(\mathrm{f}^{*}\right)(\mathrm{df} * / \mathrm{d} \delta)$ $>0$ for $\tau>$ c. Also $\mathrm{d} \pi^{\mathrm{B} \sigma} / \mathrm{d} \delta>0$, since $\partial \mathrm{R}^{\mathrm{B}} / \partial \mathrm{f}^{\sigma}=(\sigma+\tau-\mathrm{c}) \rho^{\mathrm{F}}\left(\mathrm{p}^{\sigma}\right)=-\rho^{\mathrm{F}}\left(\mathrm{p}^{\sigma}\right)<0$ and $\mathrm{df}^{\sigma} / \mathrm{d} \delta<0$. 
Proposition 5. (i) Whether or not surcharging is an option, if $N^{A}=N^{B}$, both banks agree not to surcharge and set $\tau=c$. (ii) If surcharging is banned, then $\tau \in\left(\max \left[\underline{\tau}^{B}, \tau^{A *}\right], \tau^{B *}\right)$. If $N^{B}=0$, then $\tau \in\left(c, \tau^{B *}\right)$. (iii) If surcharging is allowed and $N^{B} / N^{A}>1-f_{\tau}\left(\tau^{\sigma}, 0\right)$, then Nash bargaining would give rise to a no-surcharging agreement in which $\tau \in\left(\tau^{B b}, \tau^{B *}\right)$ and $\tau>\tau^{A *}$. If $N^{B}=0$ and 1 $f_{\tau}\left(\tau^{\sigma}, 0\right)>0$, then no agreement is possible and surcharging is the outcome.

Proof: (i) If $\mathrm{N}^{\mathrm{A}}=\mathrm{N}^{\mathrm{B}}$, then $\Pi^{\mathrm{i} *}=\mathrm{N}^{\mathrm{i}}\left(\mathrm{g}\left(\mathrm{f}^{*}\right)-\mathrm{g}(\ell)\right)$ and $\pi^{\mathrm{i} *}-\pi^{\mathrm{i} \sigma}=\mathrm{N}^{\mathrm{i}}\left(\mathrm{g}\left(\mathrm{f}^{*}\right)-g\left(\mathrm{p}^{\sigma}\right)\right)$. Since setting $\tau=$ c implies $f^{*}=p^{\mathrm{J}}$ (see Proposition 2$)$ both $\Pi^{\mathrm{i} *}$ and $\pi^{\mathrm{i} *}-\pi^{\mathrm{i} \sigma}$ are maximized. Since $\mathrm{p}^{\sigma}>\mathrm{p}^{\mathrm{J}}$, both banks will agree not to surcharge at $\tau=c$. (ii) Maximizing $\ln Z \equiv \alpha \ln \left(\Pi^{\mathrm{A} *}\right)+(1-\alpha) \ln \left(\Pi^{\mathrm{B} *}\right)$, it follows that, at a Nash bargaining equilibrium, $\tau$ satisfies

$$
\mathrm{d} \ln \mathrm{Z} / \mathrm{d} \tau=\alpha\left(\mathrm{d} \Pi^{\mathrm{A} *} / \mathrm{d} \tau\right) / \Pi^{\mathrm{A} *}+(1-\alpha)\left(\mathrm{d} \Pi^{\mathrm{B} *} / \mathrm{d} \tau\right) / \Pi^{\mathrm{B} *}=0
$$

where $\Pi^{\mathrm{i} *}>0$ and hence $\tau>\underline{\tau}^{\mathrm{B}}$. Since $\mathrm{d} \Pi^{\mathrm{A}} * / \mathrm{d} \tau=-\mathrm{N}^{\mathrm{A}} \rho^{\mathrm{F}}+\mathrm{N}^{\mathrm{B}}(\mathrm{dR} * / d \tau)<d \Pi^{\mathrm{B}} * / d \tau=-\mathrm{N}^{\mathrm{B}} \rho^{\mathrm{F}}+$

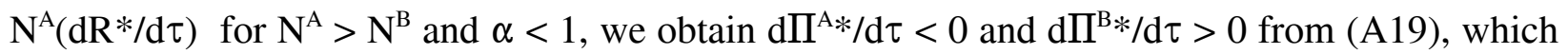
implies $\tau^{\mathrm{A} *}<\tau<\tau^{\mathrm{B} *}$ and hence $\tau \in\left(\max \left[\underline{\tau}^{\mathrm{B}}, \tau^{\mathrm{A} *}\right], \tau^{\mathrm{B} *}\right)$. If $\mathrm{N}^{\mathrm{B}}=0$, then $\underline{\tau}^{\mathrm{B}}=\mathrm{c}$ and $\tau \in\left(\mathrm{c}, \tau^{\mathrm{B} *}\right)$. (iii) If the outside option is to surcharge, then setting $\tau$ to maximize $Z^{\sigma} \equiv\left(\pi^{A *}-\pi^{A \sigma}\right)^{\alpha}\left(\pi^{B *}-\pi^{B \sigma}\right)^{1-\alpha}$ for $\alpha<1$, it follows from the first order condition, analogous to (A19), that $d \pi^{A * / d} \tau<0$ and $d \pi^{B * / d} \tau$ $>0$ and hence $\tau^{\mathrm{A} *}<\tau<\tau^{\mathrm{B} *}$. Also, an agreement not to surcharge requires $\pi^{\mathrm{i} *}-\pi^{\mathrm{i} \sigma}>0$ for $\mathrm{i}=\mathrm{A}, \mathrm{B}$. We have shown in the text that bank A prefers no surcharging (i.e. $\pi^{\mathrm{A} *}-\pi^{\mathrm{A} \sigma}>0$ ) if $\tau^{\mathrm{A} *} \leq \tau<\tau^{\sigma}$ and prefers surcharging if $\tau>\tau^{\sigma}$. Since from $(22), d \pi^{B} * / d \tau=N^{A}\left[-\left(N^{B} / N^{A}\right) \rho^{F}+d R * / d \tau\right]$, it follows using $d R * / d \tau=\rho^{F}\left(1-f_{\tau}\left(\tau^{\sigma}, 0\right)\right)$ that $d \pi^{B *} / d \tau \geq 0$ at $\tau=\tau^{\sigma}$ if and only if $N^{B} / N^{A} \leq 1-f_{\tau}\left(\tau^{\sigma}, 0\right)$. If $1-f_{\tau}\left(\tau^{\sigma}, 0\right)$ $>0$, we obtain $\mathrm{d} \pi^{\mathrm{B} * / \mathrm{d} \tau}>0$ at $\mathrm{N}^{\mathrm{B}}=0$. The results then follow as described in the text. 


\section{REFERENCES}

Canadian Competition Tribunal, 1996, Bank of Montreal (INTERAC), CT 95/02, Document \# 92a.

Demers, J., 2001, “Convenient Cash,” CMA Management, 75 (7), 54.

Donze Jocelyn and Isabelle Dubec, 2003, "The role of interchange fees in shared ATM networks", mimeo, GREMAQ (UMR 5603 CNRS) Toulouse

Duclaux, D., 1995, "Dare to be Different," American Bankers Association. ABA Banking Journal, 87 (9), 65-66.

Economides, N. and S.C. Salop, 1992, "Competition and Integration Among Complements and Network Market Structure,” Journal of Industrial Economics, 40(1), 105-123.

Fasig, L. B., 2001, "This window closed - Fleet touts replacement ATMs as always open," Providence Journal-Bulletin, March 17, Business Section, 1B

Gilbert, R. J., 1991, "On the Delegation of Pricing Authority in Shared Automatic Teller Machine Networks," in M.E. Guerin Calvert and S.S. Wilman, eds., Electronic Services Networks: A Business and Public Policy Challenge, New York: Praeger Publishing Inc., 115-144.

Gowrisankaran Gautam and John Krainer, 2003, "The Welfare Consequences of ATM Surcharges: Evidence from a Structural Entry Model”, mimeo

Hannan, T.H., 2001, "Retail fees of depository institutions, 1994-1999," Federal Reserve Bulletin, $87(1), 1-11$.

Hannan, T. H., E. K. Kiser, R. A. Prager and J. J. McAndrews, 2003, "To Surcharge or Not to Surcharge: An Empirical Investigation of ATM Pricing", Review of Economics and Statistics, forthcoming

Katz, M. and C. Shapiro, 1985, "Network Externalities, Competition, and Compatibility," American Economic Review, 75, 424-440

Laffont, JJ., P. Rey and J. Tirole, 1998, "Network competition: I. Overview and nondiscriminatory pricing," RAND Journal of Economics, 29(1), 1-37.

Massoud Nadia and Dan Bernhardt, 2002, "Rip-off ATM Surcharges," RAND journal of Economics, 33(1), 96-115

Matutes, C. and A.J. Padilla, 1994, "Shared ATM networks and banking competition," European Economic Review, 38, 1113-1138. 
McAndrews, J.J., 1998, “ATM Surcharges,” Federal Reserve Bank of New York Current Issues in Economics and Finance, 4 , 1-6.

McAndrews, J. J., 2001, “A Model of ATM pricing, Foreign fees and Surcharges,” mimeo, Federal Reserve Bank of New York.

Prager, Robin A., 2001, “The Effects of ATM Surcharges on Small Banking Organizations,” Review of Industrial Organization 18(2), 161-73.

Roseman, E., 2002, "Banking machine fees can add up", Toronto Star-Ontario Edition, March 6, 2002, E01.

Ruud, J.S. and P. Webre, 1998, "Competition in ATM Markets: Are ATM's Money Machines?" Congressional Budget Office Report (16 July), Congressional Budget Office, Washington D.C.

Salop, S.C., 1990, "Deregulating self-regulated ATM networks," Economics of Innovation and New Technology, I, 85-96.

U. S. General Accounting Office, 1998, “Automated Teller Machines: Survey Results Indicate Banks' Surcharge Fees Have Increased”, Report to the Chairman, Committee on Banking, Housing, and Urban Affairs, U.S. Senate, GAO/GGD-98-101. 